\title{
57
}

\section{Infection After Lung Transplantation}

\author{
I.L. PARADIS
}

\section{INTRODUCTION}

Infection remains the most common cause of morbidity and mortality after lung transplantation (LTx ${ }^{1-3}$. Of the 402 lung allograft procedures that were performed in 386 recipients at the University of Pittsburgh between 1982 and 1 July 1995, 187 allografts $(47 \%)$ in 180 recipients $(47 \%)$ failed (Table 1 ). Because some infections were due to more than one type of organism (e.g. bacteria plus Aspergillus), 115 infectious organisms were responsible for the failure of $97(52 \%)$ allografts in $86(48 \%)$ recipients that failed primarily due to infection. However, since 1989, infection has declined significantly from $46 \%$ to $32 \%$ as an etiology, from $80 \%$ to $53 \%$ as a cause of allograft failure, and from $85 \%$ to $54 \%$ as a cause of recipient death. This occurred because

Table 1 Causes of lung allograft failure before and after 1 January 1989 at the University of Pittsburgh

\begin{tabular}{|c|c|c|c|}
\hline & $\begin{array}{l}<1989 \\
n(\%)\end{array}$ & $\begin{array}{l}\geq 1989 \\
n(\%)\end{array}$ & $\begin{array}{l}\text { Tolal } \\
n(\%)\end{array}$ \\
\hline Infection due to: & 47 & $68^{\circ}$ & 11.5 \\
\hline Bacteria & $19(17)$ & $32(16)$ & $51(16)$ \\
\hline Fungus & $9(9)$ & $13(6)$ & $22(7)$ \\
\hline Virus & $13(12)$ & $21(10)$ & $34(11)$ \\
\hline Other & $6(6)$ & $2(1)$ & $8(3)$ \\
\hline ARDS/DAD & 9 & 36 & 45 \\
\hline Ischemic lung injury & 6 & 12 & 18 \\
\hline Ischemic airway injury & 3 & 5 & 8 \\
\hline Hemorrhage & 12 & 16 & 28 \\
\hline Acute rejection & 1 & 9 & 10 \\
\hline Obliterative bronchiolitis & 12 & 25 & 37 \\
\hline Primary graft failure & 3 & 10 & 13 \\
\hline Unknown & 0 & 10 & 10 \\
\hline Other & 10 & 19 & 29 \\
\hline Total & 103 & 210 & 313 \\
\hline Infection/etiology & $47 / 103(46)$ & $68 / 210(32)^{*}$ & $115 / 313(37)$ \\
\hline Infection/recipient death & $47 / 55(8.5)$ & $68 / 125(54)^{*}$ & $115 / 180(64)$ \\
\hline Infection/graft failure & $47 / 59(80)$ & $68 / 128(53)^{n}$ & $115 / 187(61)$ \\
\hline
\end{tabular}

i $p<0.05$ compared to beforc 1989 by chi-square analysis.

ARISS/DAD = adult respiratory distress syndrome/difuse alveolar damage. of the cumulative effect of a small decline in the prevalence of each type of infectious organism as a cause of allograft failure. Because infection has been the primary cause of failure in $53-54 \%$ of the grafts that have failed since 1989, it still remains the principal and unacceptable cause of allograft failure and death after LTx.

Infection has been the principal etiology (35\%) of allograft failure $(58 \%)$ and death $(60 \%)$ in the first year after LTx at the University of Pittsburgh (Table 2) and at other centers ${ }^{\text {? }}$. Infection has also been the principal etiology (40\%) of allograft failure $(74 \%)$ and death $(70 \%)$ more than 1 year post-transplant (Table 2). Thus, infection has been the primary cause of allograft failure at all times after LTx.

Infectious complications in LTx recipients at the University of Pittsburgh have occurred twice as frequently as in cardiac. hepatic

Table 2 Causes of lung allograft failure in the first year and later than 1 year post-transplant at the University of Pittsburgh

\begin{tabular}{|c|c|c|c|}
\hline & $\begin{array}{l}<l \text { yed } \\
n\end{array}$ & $\begin{array}{l}\geq I \text { your } \\
n(\dot{r})\end{array}$ & $\begin{array}{l}\text { Toral } \\
n\end{array}$ \\
\hline Infection due to: & 78 & 37 & 115 \\
\hline Bacteria & 3.5 & 16 & 51 \\
\hline Fungus & 14 & 8 & 22 \\
\hline Virus & 25 & 9 & 34 \\
\hline Other & 4 & 4 & 8 \\
\hline ARDS/DAD & 42 & 3 & 45 \\
\hline Ischemic lung injury & 18 & 0 & 18 \\
\hline Ischemic airway injury & 7 & 1 & 8 \\
\hline Hemorrhage & 25 & 3 & 28 \\
\hline Acute rejection & 9 & 1 & 10 \\
\hline Obliterative bronchiolitis & 4 & $3.3(35)$ & 37 \\
\hline Primary graft failure & 1.3 & 0 & 1.3 \\
\hline Unknown & 4 & 6 & 10 \\
\hline Other & 20 & 9 & 29 \\
\hline Total & 220 & 9.3 & 313 \\
\hline Infection/etiology & $78 / 220(35)$ & $37 / 93(40)$ & $115 / 31.3(37)$ \\
\hline Infection/recipicnt death & $78 / 13()(60)$ & $37 / 50(74)$ & $115 / 180(64)$ \\
\hline Infection/allograft failure & $78 / 134(58)$ & $37 / 53(70)$ & $115 / 187(61)$ \\
\hline
\end{tabular}


or renal allograft recipients who have received nearly the same immune suppression ${ }^{4}$. While the first 14 heart-lung transplant recipients experienced an average of 3.0 infections/recipient, the figure for cardiac, hepatic or renal recipients was $1.41,1.83$ or 0.98 infections/recipient, respectively ${ }^{4.5}$. At Stanford University, lung recipients experienced an average of 2.4 infections/recipient, while heart recipients experienced 0.47 infections/recipients ${ }^{6.7}$. While infection has been the primary cause of death in $<20 \%$ of long-term cardiac recipients, it has been the primary cause of death in $74 \%$ of long-term lung recipients (Table 2$)^{\circ}$. Possible reasons for these differences include the fact that the lung allograft (a) is continuously exposed to the external environment, (b) has impaired mucociliary clearance ${ }^{9-13}$, and (c) provides an HLA-incompatible microenvironment where the alveolar macrophages and lymphocytes of the recipient live in the alveoli of the donor ${ }^{14}$.

A total of 1173 significant infections have occurred in 367 'atrisk' lung recipients (survival $\geqslant 2$ days) who have been followed for 278270 days post-transplant between 1982 and 1 July 1995 . at the University of Pittsburgh (Table 3 ). This is an average of 3.23 infections/recipient, 0.43 infections $/ 100$ days of observation, or 0.0012 infections $/ 100$ days of observation/recipient. The lungs, mediastinum and pleural spaces have been the initial and/or only site for $70 \%$ of all infections (data not shown). Bacteria have been the most common organism, with pneumonia, bronchitis or sepsis having caused $62 \%$ of all infections.

When the infectious complications of the 64 recipients who received allografts prior to 1989 were compared to those of the 303 recipients who received allografts later, the number of infections/100 days of observation did not change ( 0.38 vs 0.45$)$ but the number of infections/recipient $(5.05 \mathrm{vs} 2.85)$ and the number of infections/100 days of observation/recipient (0.0059 vs 0.0015$)$ both decreased. Since 1989 the proportion of infections due to bacterial pneumonia, bronchiectasis and pneumocystis (PCP) decreased significantly $(42 \%$ vs $22 \%$ ) while those due to cytomegalovirus (CMV), bacterial bronchitis and Clostridium difficile increased significantly ( $23 \%$ vs $42 \%$ ). Bacterial bronchitis and CMV infection. however, have not changed over time when examined as a proportion of at-risk recipients $(63 \%$ vs $52 \%$ and $52 \%$ vs $45 \%$, respectively). Only infection due to $C$. difficile appears to have truly increased in frequency over time. This has most probably been due to the interval recognition of this agent as a pathogen, and also to the increasing use of antibiotics as prophylaxis of bacterial infections. The most significant finding is that the rate of infection (as defined by days of observation posttransplant) has not changed over time, but that defined by the number of infections/recipient has decreased, primarily because of a decrease in the number of episodes of bacterial pneumonia.

The risk of infection has been much higher in the first year post-transplant and $72 \%(859 / 1173)$ of all infections have occurred during that time (Table 4). This is not surprising since fresh surgical wounds are present, more intense invasive monitoring is required, and immune suppression is maximal during the first year post-transplant. The infections that occur primarily in the first year are CMV, bacterial sepsis, $C$. difficile and infections located in the mediastinum and pleural spaces. The infections that occur primarily later than 1 year post-transplant are bacterial bronchitis and bronchiectasis. All other infections are equally likely to occur at any time. The prevalence of late infection in lung recipients at 1.48 infections/recipient is 7.8 times greater than that reported for cardiac recipients, who experienced 0.19 late infections/recipient ${ }^{\sharp}$. Thus, whether comparing (a) early or recent experience or (b) early or late post-transplant periods, infection remains the most common cause of morbidity (Tables 3 and 4) and mortality (Tables 1 and 2) after LTx, despite a decrease in the prevalence of pneumonia due to bacteria and PCP.

Table 3 Types of infectious complication after lung transplantation before and after 1989 at the University of Pittsburgh

\begin{tabular}{|c|c|c|c|}
\hline & $<1989 n(\%)$ & $\geq 1989 n(\%)$ & Total $n(\%)$ \\
\hline Bacterial pneumonia & $97(30)$ & $170(20)^{*}$ & $267(22)$ \\
\hline Bacterial bronchitis & $40(12)$ & $160)(19)^{\circ}$ & 2001171 \\
\hline Bronchiectasis & $13(4)$ & $6(<1)$ & $19(2)$ \\
\hline Fungal infection & $18(7)$ & $50(6)$ & $68(6)$ \\
\hline Cytomegalovirus & $33(10)$ & $136(16)^{*}$ & $169(14)$ \\
\hline Pneumocystis & $24(7)$ & $11(1)^{\circ}$ & $35(3)$ \\
\hline Lymphoproliferative disease & $6(2)$ & $16(3)$ & $22(3)$ \\
\hline Herpes simplex & $12(4)$ & $43(5)$ & $55(5)$ \\
\hline Viral hepattitis & $2(<1)$ & $9(1)$ & $11(1)$ \\
\hline Other viruses & $5(2)$ & $39(5)$ & $44(4)$ \\
\hline Mediastinitis & $11(3)$ & $3(<1)$ & $14(1)$ \\
\hline Empyema & $4(1)$ & $8(1)$ & $12(1)$ \\
\hline Bicterial sepsis & $34(10)$ & $100(9)$ & $134(11)$ \\
\hline Sinusitis & $7(2)$ & $23(3)$ & $30(3)$ \\
\hline C. difficile colitis & $2(4)$ & $59\langle 7\rangle^{*}$ & $61(5)$ \\
\hline Other & 12 & 20 & $32(3)$ \\
\hline Total infections & 320 & 853 & 1173 \\
\hline At-risk recipients & 64 & 303 & 367 \\
\hline Days of observation & 85146 & 193124 & 278270 \\
\hline Infections/recipient & 5.05 & 2.85 & 3.23 \\
\hline Infections/100 days of observation & 0.38 & 0.45 & 0.43 \\
\hline Infections/recipient/ 100 days of observation & 0.0059 & 0.0015 & 0.0012 \\
\hline
\end{tabular}

$p<0.015$ compired an betione 1989 by chi-square. 
Table 4 Types of infectious complication in the first year and later than 1 year post-lung transplantation at the University of Pittsburgh

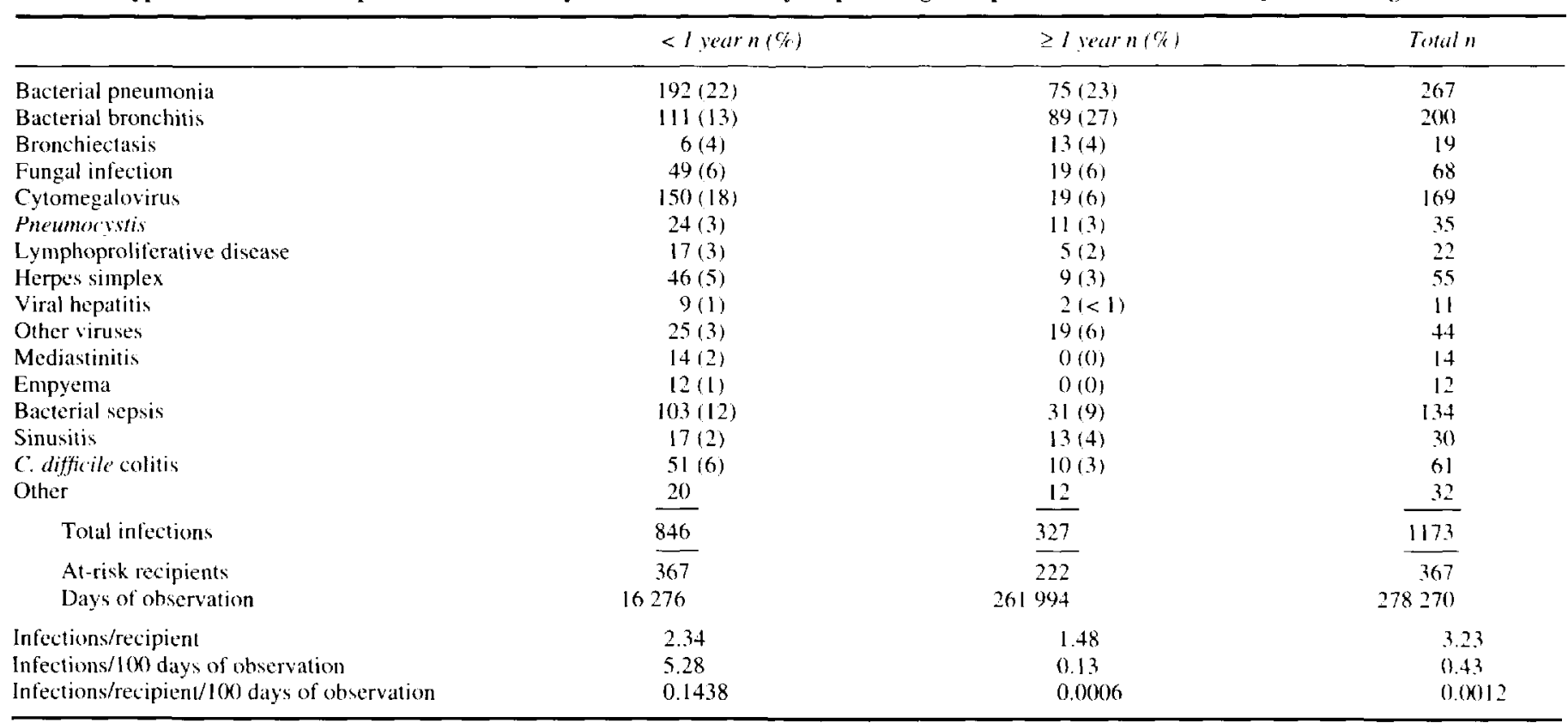

\section{SURVEILLANCE FOR INFECTION}

Prior to transplantation (in the recipient) and at the time of transplantation (in the donor), the serologic status of recipient and donor for CMV; Epstein-Barr virus (EBV); varicella virus; herpes simplex virus (HSV); Toxoplasma; hepatitis A, B and C; and human immunodeficiency (HIV) type 1 virus are determined. Sputum for cultures and stains for bacteria and fungus are obtained every 3 months from candidates with septic lung disease. A transplant procedure can be performed when Pseudomonas species are sensitive to more than one class of anti-pseudomonal antibiotics, or if Aspergillus species are not present in respiratory tract secretions.

At the time of transplantation, specimens for cultures and stains for fungi and bacteria are obtained from airways of both donor and recipient ${ }^{15,16}$. This information is useful in assessing the susceptibility of the recipient to develop infection with bacteria or fungus posttransplantation. Another aerobic and fungal sputum culture is obtained prior to extubation. Chest radiographs are obtained daily, with the frequency decreasing to once or twice a week by the end of the initial hospital stay. Fiberoptic bronchoscopy with bronchoalveolar lavage (BAL) and transbronchial lung biopsy (TBBx) is performed at least once, and as often as weekly, during the initial hospital stay, every 3 months during the first year, every 4 months during the second year, twice a year thereafter, and whenever infection or rejection in the allograft is suspected ${ }^{17}$. Recipients record their spirometry at home and report any consistent, unexplained $>10 \%$ decrease in the FEV, over a 1-2-week period ${ }^{18}$. If a decrease in home spirometry is confirmed by spirometry in a pulmonary function laboratory, a re-evaluation, which includes a bronchoscopy with BAL and TBBx, is performed at the transplant center.

\section{BACTERIAL PNEUMONIA}

\section{Definition}

The diagnosis of bacterial pneumonia has been made by: (a) the presence of a new or predominant organism by Gram stain of the sputum in association with fever or new or increased radiographic infiltrates, (b) histologic criteria. or (c) the presence of $>10^{4} \mathrm{cfu} / \mathrm{ml}$ of cultured BAL fluid and $/$ or $>5 \%$ of $\mathrm{BAL}$ cells containing intracellular bacteria ${ }^{14} 2 y$.

\section{'Prophylactic' antibiotic regimens}

Although still the most common infectious complication after LTx, there has been a significant decrease since 1989 in the prevalence of bacterial pneumonia (a) as a proportion of all infectious complications ( $38 \%$ vs $20 \%$; Table 3 ), (b) as a proportion of at-risk recipients (78\% vs $33 \%$; Table 5 ) and (c) in regard to the number of episodes/at-risk recipient ( 1.50 vs 0.56 ; Table 5 ). This coincides with the introduction of an antibiotic regimen tailored to the results of aerobic cultures of the donor and recipient airways obtained at the time of transplantation ${ }^{15,16}$ and with the introduction of TBBx to distinguish between diffuse alveolar damage, infection and/or rejection ${ }^{17,30-36}$. Prior to 1989, recipients received only cefamandole $1 \mathrm{~g}$ every $8 \mathrm{~h}$ for $72 \mathrm{~h}$ post-transplant. Since that time, recipients without pretransplant septic lung disease have received clindamycin and ceftazidine immediately post-transplant. If the recipient and donor airway cultures are sterile, these antibiotics are stopped at $72 \mathrm{~h}$ post-transplant. If they contain oral flora organisms, clindamycin is continued for 10 days. If they contain Staphylococcus, clindamycin is continued, and vancomycin is added to complete a 10-day course if the 
Table 5 Morbidity and mortality of bacterial pneumonia at the University of Pittsburgh before and after 1989

\begin{tabular}{llll}
\hline & $<1989$ & $\geq 1989$ & $T o(a l$ \\
\hline Affected recipients/at-risk recipients & $50 / 64(78 \%)$ & $101 / 303(33 \%)^{\circ}$ & $151 / 367(41 \%)$ \\
Episodes/at-risk recipient & $97 / 64(1.50)$ & $170 / 303(0.56)^{*}$ & $1767 / 367(0.73)$ \\
Episodes/affected recipient & $97 / 50(1.94)$ & $170 / 101(1.70)$ & $267 / 151(1.78)$ \\
Mortality/episode & $10 / 97(10 \%)$ & $23 / 170(13 \%)$ & $3.269(12 \%)$ \\
Mortality/at-risk recipient & $10 / 64(17 \%)$ & $23 / 303(8 \%)$ & $3.3 / 367(9 \%)$ \\
Mortality/affected recipient & $10 / 50(20 \%)$ & $23 / 101(2.3 \%)$ & $3.3 / 151(22 \%)$ \\
\hline
\end{tabular}

r $p 0.0001$ compared to before 1989 by chi-square analysis.

Staphylococcus is methicillin-resistant. If these cultures contain Gram-negative organisms, clindamycin is discontinued, ceftazidime is continued, and another antibiotic with Gram-negative coverage is added to the regimen. Alternatively, the ceftazidime and clindamycin may both be discontinued and two new culturedirected antibiotics with Gram-negative coverage are administered for 10 days.

For recipients with septic lung disease, three or four antibiotics active against Pseudomonas aeruginosa and/or Burkholderia cepacia are begun immediately pretransplant and continued for two full weeks or longer until a positive clinical outcome is certain. The choice of antibiotics is based on the antibiotic sensitivities of the organism(s) present in the sputum of the recipient pretransplant. These recipients also receive less immune suppression. The level of cyclosporin or tacrolimus is maintained at approximately half of that in the non-infected recipient. Azathioprine and corticosteroids are withheld unless more than two episodes of histologically documented acute rejection occur, or unless corticosteroids are necessary to avoid corticosteroidinduced adrenal suppression (secondary to pretransplant use of corticosteroids). With this approach the prevalence of bacterial pneumonia in the first 2 weeks post-transplant has decreased significantly from $47 \%$ to $9 \%$ (Table 6).

\section{Prevalence}

The prevalence of bacterial pneumonia has also decreased significantly between postoperative days (POD) 15 and 180 after LTx. This is beyond the perioperative period (i.e. POD 1-14) where an effect due to the antibiotic regimen employed (according to the results of cultures obtained from the airways of the

Table 6 Change in the prevalence of bacterial pneumonia before and after 1989 at different time periods after lung transplantation at the University of Pittshurgh

\begin{tabular}{|c|c|c|c|}
\hline $\begin{array}{l}\text { Post-transplant } \\
\text { time interials }\end{array}$ & $\begin{array}{l}<1989 \\
n(\%)\end{array}$ & $\begin{array}{l}\geq 1989 \\
n(\%)\end{array}$ & P-ralue \\
\hline$\leq 14$ days & $30 / 6+(47)^{*}$ & $28 / 303(9)$ & $<0.0001$ \\
\hline $15-90$ days & $21 / 57(37)$ & $50 / 302(17)$ & 0.0008 \\
\hline $91-180$ days & $12 / 40(30)$ & $20 / 253(8)$ & 0.0001 \\
\hline 181. 365 days & $6 / 36(17)$ & $23 / 219(8)$ & n.s. \\
\hline $1-2$ years & $7 / 33(21)$ & $34 / 189(18)$ & n.s. \\
\hline $2-3$ years & $9 / 31(29)$ & $7 / 128(5)$ & 0.0003 \\
\hline $3-4$ years & $5 / 29(17)$ & $4 / 66\langle 6\}$ & n.s. \\
\hline$>4$ years & $7 / 26(27)$ & $3 / 27(11)$ & n.s. \\
\hline
\end{tabular}

"Data expressed as number of episodes/at-risk recipients. donor and recipient at the time of transplantation) would not be expected.

This reduction in the prevalence of bacterial pneumonia between POD 15 and 180 is most probably due to the use of bronchoscopy with BAL and TBBx to distinguish between diffuse alveolar damage, infection and/or acute rejection. Information gained from bronchoscopy has avoided empiric pulses of augmented immune suppression to treat clinical rejection, and has allowed for lower levels of maintenance immune suppression when rejection has not been present. Less immune suppression reduces the risk of bacterial pneumonia.

\section{Relationship with obliterative bronchiolitis (chronic lung rejection)}

Between 6 months and 2 years post-transplant the prevalence of bacterial pneumonia has been between $8 \%$ and $21 \%$. and this has been unaffected by advances in the care of recipients. This is the period of time, however, when lung recipients are most at risk of developing obliterative bronchiolitis $(\mathrm{OB})^{37.38}$. This complication is a significant risk factor for developing bacterial pneumonia or bronchitis $>90$ days post-transplant (Table 7 ). In the 291 recipients who survived $>90$ days post-transplant, pneumonia occurred twice as frequently in recipients with $\mathrm{OB}$ compared to those without $\mathrm{OB}$ ( 1.03 vs 0.53 episodes/recipient). Bronchitis occurred five times more frequently in recipients with (as compared to those without) $O B$ ( 1.12 vs 0.21 episodes/recipient). In the 155 recipients who survived $>2$ years post-transplant, pneumonia $0 c-$ curred twice as frequently in recipients with $\mathrm{OB}(1.01$ vs 0.45 episodes/recipient), and bronchitis occurred three times more frequently in those with $\mathrm{OB}$ ( $1.15 \mathrm{vs} 0.38$ episodes/recipient). Thus, both early and late after LTx, the majority of the episodes of pneumonia and bronchitis due to bacteria have occurred in recipients with chronic rejection.

Additionally, the number of recipients who developed pneumonia or bronchitis due to bacteria was affected by the presence of chronic rejection. For the 291 recipients who survived $>90$ days post-transplant, pneumonia developed in $50 \%$ of the recipients with $\mathrm{OB}$, but in only $30 \%$ of recipients without $\mathrm{OB}(p=0.001)$ (Table 7). Bronchitis occurred in $54 \%$ of recipients with OB, but in only $21 \%$ of those without $\mathrm{OB}(p<0.0001)$. For those recipients who survived $>730$ days post-transplant, pneumonia developed in $50 \%$ of those with $\mathrm{OB}$, but in only $32 \%$ of those without $\mathrm{OB}$ $(p=0.02)$. Similarly, bronchitis developed in $56 \%$ who developed OB but in only $29 \%$ without $\mathrm{OB}(p=0.0008)$. Thus, both early and late after LTx, significantly more episodes occurred and more re- 
cipients experienced bacterial pneumonia and/or bronchitis when chronic rejection was present.

It is also true, however, that many recipients with $O B$ do not develop pneumonia or bronchitis and, conversely, many recipients without $\mathrm{OB}$ do develop these infections. For recipients who survived $>90$ days post-transplant, $50 \%$ of those with $\mathrm{OB}$ have never developed pneumonia and $30 \%$ of those without $O B$ have developed pneumonia. Similarly, for recipients who survived $>90$ days post-transplant, $46 \%$ of those with $O B$ never developed bronchitis and $21 \%$ of those without $\mathrm{OB}$ have experienced at least one episode of bronchitis (Table 7).

\section{Specific bacterial infections}

Pseudomonas aeruginosa and Staphylococcus aureus, either alone or in combination with other organisms, have been responsible for the majority of the episodes of pneumonia and bronchitis that have occurred at all time points post-transplant (Table 8). P. aeruginosa was the agent responsible for $35 \%$ and $38 \%$ of the episodes of pneumonia and bronchitis, respectively, that occurred in recipients who survived $>90$ days post-transplant (Table 8). $P$. aeruginosa was the agent responsible for $37 \%$ of the episodes of pneumonia and $37 \%$ of the episodes of bronchitis that occurred in recipients who survived $>730$ days post-transplant. S. aureus was responsible for $20 \%$ and $22 \%$ of the episodes of pneumonia and bronchitis, respectively, that occurred in recipients who survived $>90$ days post-transplant. This organism caused $18 \%$ and $19 \%$ of the episodes of pneumonia and bronchitis, respectively, that occurred in recipients who survived $>730$ days post-transplant. These two organisms have been responsible for $55-60 \%$ of all of the episodes of pneumonia and bronchitis that have occurred in these recipients.

The likelihood that $P$. aeruginosa was the agent responsible for an episode of pneumonia or bronchitis, however, was unaffected
Table 7 Relationship of bacterial pneumonia (BP) and bacterial bronchitis $(\mathrm{BB})$ to chronic rejection $(\mathrm{CR})$ in recipients who survived $>90$ days or $>2$ years post-transplant at the University of Pittsburgh

\begin{tabular}{|c|c|c|}
\hline \multirow[b]{2}{*}{ Survival } & \multicolumn{2}{|c|}{ Episedes/recipient } \\
\hline & $>90$ days & $>2$ years \\
\hline \multicolumn{3}{|c|}{ Bacterial pneumonia } \\
\hline $\mathrm{CR}+$ & $110 / 107=1.03$ & $79 / 78=1.01$ \\
\hline $\mathrm{CR}-$ & $98 / 184=0.53$ & $35 / 77=0.45$ \\
\hline Total & $208 / 291=0.71$ & $114 / 155=0.74$ \\
\hline \multicolumn{3}{|c|}{ Bacterial bronchitis } \\
\hline $\mathrm{CR}_{+}$ & $120 / 107=1.12$ & $90 / 78=1.15$ \\
\hline $\mathrm{CR}_{-}$ & $38 / 184=0.21$ & $29 / 77=0.38$ \\
\hline \multirow[t]{3}{*}{ Total } & $158 / 291=0.54$ & $119 / 155=0.77$ \\
\hline & \multicolumn{2}{|c|}{ Affocted recipients (\%) } \\
\hline & $>90$ days & $>2$ years \\
\hline \multicolumn{3}{|c|}{ Bacterial pneumonia } \\
\hline $\mathrm{CR}+\mathrm{BP}+$ & $54(19)^{\circ}$ & $39(25)^{\circ}$ \\
\hline $\mathrm{CR}+, \mathrm{BP}-$ & $53(18)$ & $39(25)$ \\
\hline $\mathrm{CR}-\mathrm{BP}+$ & $56(19)$ & $25(16)$ \\
\hline $\mathrm{CR}-, \mathrm{BP}-$ & $128(44)$ & $52(34)$ \\
\hline Total & $\overline{291(100)}$ & $\overline{155(100)}$ \\
\hline \multicolumn{3}{|c|}{ Bacterial bronchitis } \\
\hline $\mathrm{CR}+, \mathrm{BB}+$ & $58(20)^{\star}$ & $44(28)^{*}$ \\
\hline $\mathrm{CR}+, \mathrm{BB}-$ & $49(17)$ & $34(22)$ \\
\hline $\mathrm{CR}-\mathrm{BB}+$ & $38(13)$ & $22(14)$ \\
\hline $\mathrm{CR}-\mathrm{BB}-$ & $146(50)$ & $55(36)$ \\
\hline Total & $\overline{291(100)}$ & $155(100)$ \\
\hline
\end{tabular}

" $p<0.05$ by chi-square analyxis.

by the presence of chronic rejection (Table 8 ). Pneumonia or bronchitis due to $P$. aeruginosa occurred in $33-35 \%$ of the episodes when OB was present, and in $39-47 \%$ when it was not

Table 8 Episodes of pneumonia or bronchitis due to Pseudomonas aeruginosa and Staphylococcus aureus in recipients with or without chronic rejection (CR) who survived $>90$ or $>730$ days post-transplant at the University of Pittsburgh

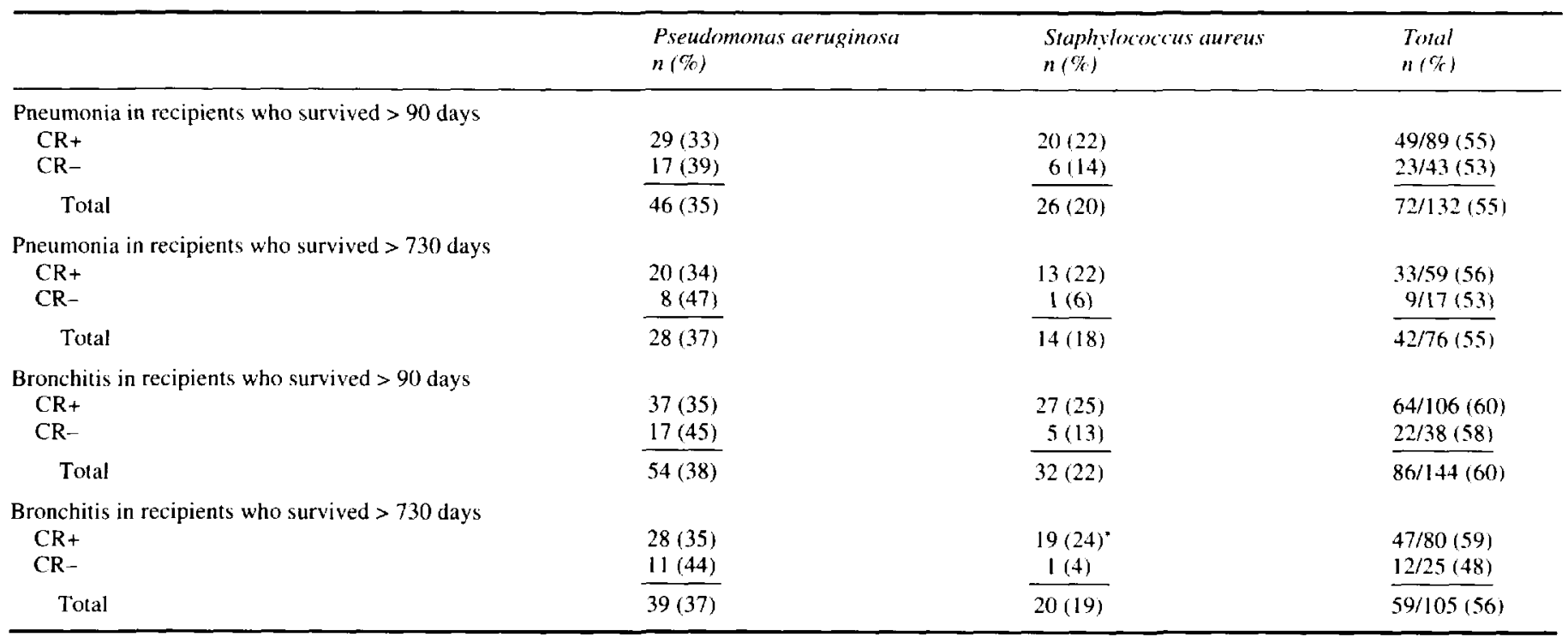

" $p=0.05$ compared to no chronic rejection by chi-square. 
present. For unclear reasons, however, $S$. aureus was more clearly associated with OB. Pneumonia or bronchitis due to this organism occurred in $22-25 \%$ of the episodes in which OB was present, but it was the causative organism in only $4-14 \%$ of the episodes in which $\mathrm{OB}$ was not present. Thus, although $P$. aeruginosa has been the most common organism responsible for episodes of pneumonia or bronchitis, it is equally likely to occur in recipients with or without chronic rejection. $S$. aureus has been the second most common cause of pneumonia or bronchitis, and it has been more frequently observed in recipients with $O B$. Thus, any bacterial infection, particularly that due to $S$. aureus, occurring $>90$ days post-transplant, suggests the co-presence of chronic rejection. An evaluation to detect this process should be performed after the infection has been treated (because the inflammation caused by infection can result in pulmonary function and histologic changes that make $O B$ difficult to identify clinically and histologically).

Because of the association of $\mathrm{OB}$ with recurrent airway and parenchymal bacterial infection, bacteria in the airways of recipients with $O B$ have been treated with 'prophylactic' antibiotics. Recipients with oral flora or methicillin-sensitive Staphylococcus organisms receive oral cephalexin $500 \mathrm{mg}$ four times daily, and those with sensitive $P$. aeruginosa receive oral ciprofloxacin $500 \mathrm{mg}$ twice daily and aerosolized tobramycin $80 \mathrm{mg}$ three times a day for 10 days/month. Aerosol colistin (30-75 mg two or three times a day) is substituted for tobramycin when the Pseudomonas organism(s) is (are) resistant to tobramycin. Occasional recipients receive intravenous (i.v.) antibiotics 10 days/month to suppress infection/colonization by organisms resistant to the above measures. The reduction in the prevalence of bacterial pneumonia more than 2 years post-transplant from $17-29 \%$ per year before 1989 to $5-11 \%$ per year since 1989 (which is statistically significant between 2 and 3 years post-transplant) is most probably due to these measures (Table 6).

Multiple antibiotic-resistant strains of $P$. aeruginosa and/or Burkholderia cepacia have been defined as organisms sensitive to $\leq 1$ class of antipseudomonal antibiotics (such as an aminoglycoside, third-generation cephalosporin, fluoroquinolones, antipseudomonal penicillin, carbapenems or monobactams). These multiply antibiotic-resistant bacteria are thought to be markers of increased morbidity/mortality. In the Toronto series, $46 \%$ of recipients with $B$. cepacia in their pretransplant sputum died, whereas none of the recipients with only $P$. aeruginosa in their pretransplant sputum died of infection due to this organism posttransplant ${ }^{39}$. One uncontrolled study has suggested an improved outcome for recipients with cystic fibrosis who undergo pretransplant maxillary sinus antrostomy with repeated sinus lavage with tobramycin ${ }^{40}$. Other perform such procedures plus ethmoidectomy only if clinically significant sinus infections occur in the post-transplant period.

Although the prevalence of early and late episodes of bacterial pneumonia has decreased significantly since 1989 , bacterial pneumonia still occurs in $33 \%$ of lung recipients, each affected recipient averages 1.7 episodes, and each at-risk recipient averages 0.56 episodes of bacterial pneumonia (Table 5). Additionally, there is a relationship between the use of 'prophylactic' antibiotics and the development of antibiotic resistance ${ }^{41-48}$. The use of clindamycin has also been implicated in the subsequent development of enterocolitis due to $C$. difficile ${ }^{49}$. Bacterial pneumonia has been treated with culture-specific antibiotics for at least 2 and sometimes up to 4 weeks, depending on the rate of clinical resolution. Additionally, the levels of immune suppression are reduced modestly. Usually, the target blood level of cyclosporin or tacrolimus is reduced by about $33 \%$, azathioprine is held until clinical recovery is apparent, and the dose of corticosteroids is reduced to levels necessary to prevent a hypoadrenal state.

The results from this treatment approach as assessed by mortality have not changed over time. The mortality per episode $(10-13 \%)$ and per affected recipient $(20-23 \%)$ before and after 1989 have not changed significantly (Table 5). Bacterial pneumonia remains a fairly lethal disease with a mortality of $12 \%$ per episode, $9 \%$ per at-risk recipient, and $22 \%$ per affected recipient. Thus, while this infection can usually be avoided, accurately diagnosed and reliably treated in most recipients, there is room for new strategies both in prevention and in treatment.

\section{CYTOMEGALOVIRUS (CMV)}

\section{Definition}

As in any host, CMV in LTx recipients is a pathogen with protean manifestations ${ }^{50-57}$. Nevertheless, clinical illness due to CMV can be defined by the presence of an infection, syndrome or disease, which may or may not be symptomatic. CMV infection has been defined by the presence of CMV in cultures obtained from any body site in the absence of symptoms and cytologic or histologic changes typical of CMV. CMV syndrome has been defined as a positive culture for CMV from any body site, plus symptoms typical of CMV infection, usually associated with leukopenia and $>3 \%$ atypical lymphocytes in the peripheral blood smear, but without cytologic or histologic changes typical of CMV. CMV disease has been defined by the presence of a positive culture of CMV obtained from any body site plus the presence of intracellular inclusions typical of CMV in cells or tissue obtained from any body site. Symptomatic CMV disease has included the findings associated with a CMV syndrome. In the following discussion, the few episodes ( $n=5$ ) of CMV syndrome in the University of Pittsburgh experience have been included with the group with CMV disease, because these occurrences were treated as though disease was present.

\section{Prevalence}

Using these definitions the prevalence of CMV illness has been $47 \%$, with 169 episodes in 359 allografts in 350 recipients who survived $\geqslant 14$ days post-transplant at the University of Pittsburgh (Table 9). It has accounted for $14 \%$ of all infectious complications, and has been the next most common pathogen encountered after bacteria (Table 3). CMV has been recovered as early as the first day post-transplant and has caused disease as early as 16 days post-transplant. Mean and median occurrences were 48 and 41 days post-transplant, respectively, before the use of ganciclovir for prophylaxis. Because of the effectiveness of ganciclovir prophylaxis, CMV illness now occurs significantly later $(p<0.001$ by Mann-Whitney) with a mean and median occurrence at 141 and 131 days post-transplant, respectively, which is almost always after the prophylaxis has stopped. Nevertheless, CMV 
Table 9 Effect of prophylaxis with ganciclovir or CMV-negative blood products on the prevalence of CMV illness after lung transplantation at the University of Pittsburgh

\begin{tabular}{lccc}
\hline & \multicolumn{3}{c}{ Prophylaxis } \\
\cline { 2 - 4 } & No & Yes & Total \\
\hline Allografts at risk & 94 & 265 & 359 \\
Infection & 16 & 59 & 75 \\
Disease & & & \\
$\quad$ Pneumonia only & 24 & 41 & 65 \\
Gastrointestinal only & 3 & 5 & 8 \\
Disseminated & 6 & 10 & 16 \\
Syndrome & 0 & 5 & 5 \\
\cline { 2 - 4 } Illness (total) & 49 & 120 & 169 \\
Infection/allograft & $17 \%$ & $22 \%$ & $21 \%$ \\
Discase/allograft & $35 \%$ & $23 \% *$ & $26 \%$ \\
Illness/allograft & $52 \%$ & $45 \%$ & $47 \%$ \\
\hline
\end{tabular}

$" n=0.03$ compared to no prophylaxis by chi-square.

illness is still usually an early infection, as $89 \%$ of all episodes have occurred in the first year post-transplant (Table 4). De-novo CMV pneumonia, however, has occurred as late as 2338 days post-transplant, and CMV infection has occurred as late as 1533 days post-transplant. As it accounts for $6 \%$ (Table 4 ) of all infections that have occurred $>1$ year post-transplant, CMV can never be excluded from the differential diagnosis, especially since treatment with ganciclovir is very safe and effective.

Of the 169 episodes of CMV illness, 75 (44\%) have been due to infection, $94(46 \%)$ have been due to disease, and 15 resulted in death (Table 10A). The majority $(84 \%)$ of the episodes of infection have occurred in seropositive recipients $(\mathrm{R}+)$. The majority $(62 \%)$ of the episodes of disease have occurred when the donor was seropositive (D+). The majority $(73 \%)$ of deaths have occurred in seronegative recipients ( $R-)$, especially when the allograft came from a seropositive donor (R-D+) $(47 \%)$.

Seronegative recipients who received lungs from seronegative donors (R-D-) have had the lowest risk of infection $(6 \%)$, disease $(16 \%)$ and illness $(22 \%)$, but their risk of death from CMV has been significant $(5 \%)$ (Table $10 \mathrm{~B}$ ). $\mathrm{R}-\mathrm{D}+$ recipients have had the lowest risk of infection ( $4 \%$ ) but the highest risk of disease $(47 \%)$ and death from CMV $(9 \%)$. $\mathrm{R}+\mathrm{D}$ - recipients have had the highest risk of infection (38\%) and the lowest risk of disease $(17 \%)$ and death from CMV (<1\%). $\mathrm{R}+\mathrm{D}+$ recipients have had an intermediate risk of infection $(29 \%)$ and disease $(31 \%)$, but their risk of death from CMV has been low (1.3\%).

Episodes of CMV illness most likely represented disease when recipients were seronegative ( $\mathrm{R}-$ ) (at $72 \%$ for $\mathrm{R}-\mathrm{D}-$, and at $90 \%$ for $\mathrm{R}-\mathrm{D}+$ recipients) (Table $10 \mathrm{C}$ ). These episodes were also more likely to result in death $(19 \%)$ as compared to when the recipient was seropositive $(\mathrm{R}+)(2 \%)$. The majority $(69 \%)$ of the episodes of CMV illness in $\mathrm{R}+\mathrm{D}$ - recipients represented infection, whereas the likelihood of infection or disease was equal in $\mathrm{R}+\mathrm{D}+$ recipients. This information is similar to that previously reported ${ }^{51} 5$. The sites of occurrence of CMV disease and infection have been biased by a tendency to evaluate the lung allograft more frequently and intensively compared to other organs. Nevertheless, the allograft has been the overwhelming primary site of CMV illness, with $85 \%$ of the episodes of CMV disease arising in the

Table 10 Prevalence and severity of CMV illness by pretransplant recipient $(R)$ and donor (D) serologic status for CMV at the University of Pittsburgh

A: Number of at-risk recipients and episodes of $C M V$ infection, disease, illness and deaths due to $C M V$

\begin{tabular}{|c|c|c|c|c|c|}
\hline Serologic status & Recipients at risk & Infection & Disease & Ilness & Deaths \\
\hline R-D- & 82 & 5 & 13 & 18 & 4 \\
\hline $\mathrm{R}-\mathrm{D}+$ & 75 & 4 & 35 & 39 & 7 \\
\hline $\mathrm{R}+\mathrm{D}-$ & 107 & 41 & 18 & 59 & 1 \\
\hline $\mathrm{R}+\mathrm{D}+$ & 75 & 22 & 23 & 45 & 1 \\
\hline Unknown & 20 & 3 & 5 & 8 & 2 \\
\hline Total & 359 & 75 & 94 & 169 & 15 \\
\hline
\end{tabular}

B: Proportion of at-risk recipients who experienced an episode of, or died as a result of, CMV illnews

\begin{tabular}{|c|c|c|c|c|c|}
\hline Serologic status & Recipients at risk & Infertion (\%) & Disease (\%) & Ilness (\%) & Deaths (\%) \\
\hline $\mathrm{R}-\mathrm{D}-$ & 82 & 6 & 16 & 22 & 5 \\
\hline R-D+ & 75 & 5 & 47 & 52 & 9 \\
\hline $\mathrm{R}+\mathrm{D}-$ & 107 & 38 & 17 & 55 & 1 \\
\hline $\mathrm{R}+\mathrm{D}+$ & 75 & 29 & 31 & 60 & 1 \\
\hline Unknown & 20 & 15 & 25 & 40 & 10 \\
\hline Total & 359 & 21 & 26 & 47 & 4 \\
\hline
\end{tabular}

C: Proportion of episodes of $C M V$ illness that resulted in infection, disease or death

\begin{tabular}{llll}
\hline Serologic slatus & Infection (\%) & Disease (\%) & Deaths(\%) \\
\hline R-D- & $5 / 18(28)$ & $13 / 18(72)$ & $4 / 18(22)$ \\
R-D+ & $4 / 39(10)$ & $35 / 39(90)$ & $7 / 39(18)$ \\
R+D- & $41 / 59(69)$ & $18 / 59(31)$ & $1 / 59(2)$ \\
R+D+ & $22 / 45(49)$ & $23 / 45(51)$ & $1 / 45(2)$ \\
\hline
\end{tabular}


allograft either as isolated CMV pneumonitis $(n=65)$ or as part of a disseminated process ( $n=16$ ) (Table 9).

\section{Clinical features}

Signs and symptoms of lung disease have ranged from none (with normal oxygenation and a normal chest radiograph) to fever, dyspnea, hypoxemia and diffuse radiographic infiltrates. Because the clinical presentation of CMV pneumonitis can be similar to that of acute rejection, these entities can be reliably distinguished from each other only by TBBx and BAL. In two instances, CMV pneumonitis has resulted in severe alveolar hemorrhage with hemoptysis.

The organ next most likely to be involved has been the gastrointestinal tract. In $8 \%$ of affected recipients the only site of disease has been in the colon and/or stomach. Another $17 \%$ of affected recipients also developed gastrointestinal disease as part of a disseminated illness. Symptoms associated with gastrointestinal disease have included anorexia, nausea, vomiting, weight loss, abdominal pain and/or diarrhea.

In the vast majority, CMV disease has been a single event that appears to have established or re-established long-lasting immunity. However, recurrent CMV disease has occurred in six recipients, one of which was due to ganciclovir resistance. In the other instances the recipient's immune system appears to have been unable to generate an effective immune response against this organis $^{58}$.

\section{Detection and diagnosis}

Advances in detection and diagnosis have improved the prognosis of CMV infection after transplantation. The greater use of endoscopy with biopsy of the allograft or the gastrointestinal tract has increased the rate of detection of CMV disease with minimal morbidity and no mortality to the recipient ${ }^{17}$. Whereas conventional cultures on foreskin fibroblasts often required weeks to become positive, the shell vial assay and culture have allowed detection of virus antigen in 48 hours in the majority of specimens where a significant virus burden has been present ${ }^{59.60}$. Cytologic examination of BAL cells for the detection of the typical cytopathic effects of CMV has been a rapid and specific (but not sensitive) assay to detect CMV disease in cancer patients and in lung and bone marrow recipients ${ }^{61-63}$.

The significance of detecting CMV-specific pp65 protein by immunofluorescence with monoclonal antibodies on peripheral blood neutrophils and monocytes is being evaluated clinically ${ }^{64.65}$. This protein appears to be associated with active virus replication, which would indicate active CMV infection ${ }^{66}$. The advantages of this assay are that it is quantitative, rapid, easy to perform, and sensitive and specific for CMV. In fact it appears to be more sensitive than the shell vial method for the detection of CMV in blood neutrophils ${ }^{67}$. The clinical characteristics of the assay, however, are not quite as reliable (when compared to conventional culture) with a sensitivity of $87 \%$, specificity of $92 \%$, negative predictive value of $98 \%$, and positive predictive value of $65 \%$. Additionally, events in the allograft do not always mirror those in peripheral blood. CMV pneumonitis has been observed when the CMV pp65 antigen assay performed on peripheral blood leukocytes was negative (personal experience). Nevertheless, the assay has merit, and the correlation of its clinical characteristics (for the detection of CMV pp65 protein in BAL cells of lung recipients) with the presence of CMV infection and disease by conventional methods should be evaluated.

The polymerase chain reaction to detect $\mathrm{CMV}$ has not gained wide acceptance because it is more complicated, expensive, and time-consuming compared to the methods discussed above ${ }^{68.69}$. Additionally, the assay is probably too sensitive to be useful clinically because it appears to detect latent virus, which is usually not a concern clinically.

\section{Treatment}

Advances in treatment have also improved the prognosis of CMV disease after LTx. CMV disease has been treated with ganciclovir ( $5 \mathrm{mg} / \mathrm{kg}$ twice a day i.v.) for 2 full weeks with the dose adjusted for renal function. Compared to historical controls at the University of Pittsburgh, who received no therapy or only acyclovir, this regimen has significantly reduced the mortality of CMV disease from $45 \%$ to $7 \%$.

\section{Prevention}

Advances in prevention have been due to the use of: (a) CMVnegative blood products for R-D- recipients and of (b) ganciclovir in all other combinations of seropositive donors/recipients. These efforts occurred because CMV illness and disease had been a major source of morbidity post-LTx with a prevalence of $52 \%$ and $35 \%$, respectively, in the absence of prophylaxis (Table 9) and because CMV appeared to increase the risk of allograft rejec$\operatorname{tion}^{56,70-72}$. Gene products of CMV appear to block the ability of cyclosporin to inhibit interleukin-2 (IL-2) transcription ${ }^{73}$. Restoration of IL-2 production despite the presence of cyclosporin could result in normal $T$ cell function with resultant allograft rejection. With prophylaxis the prevalence of CMV disease has decreased significantly from $35 \%$ to $23 \%$ (Table 9).

In $\mathrm{R}-\mathrm{D}$ - recipients the use of $\mathrm{CMV}$-negative blood products has significantly decreased the prevalence of CMV disease from 75\% to $9 \%$ (Table 11). Some CMV illness has continued to occur in this group, possibly because of false-negative CMV antibody titers in some allograft donors/recipients and/or blood donors. Three episodes of CMV disease occurred after retransplantation where large amounts of CMV-negative blood products were used.

Table 11 Effect of CMV-negative blood products on risk of primary CMV illness in seronegative donors and recipients at the University of Pittsburgh

\begin{tabular}{lll}
\hline & \multicolumn{2}{c}{ Blood product } \\
\cline { 2 - 3 } & Unknown & Negative \\
\hline R-D-Recipients & 8 & 74 \\
Infection & 0 & 5 \\
Disease & $\frac{6(75 \%)}{6(75 \%)}$ & $\frac{7(9 \%)^{* \dagger}}{12(16 \%)^{+}}$ \\
Illness & 6 & \\
\hline * Includes three re-transplants. \\
$+p<0.002$ compared to CMV unknown bloxd products by chi-square.
\end{tabular}


It is likely that these episodes were transmitted from blood products that were not obtained from truly CMV-negative donors. Perhaps ganciclovir prophylaxis should also be used in retransplant R-D-situations.

Since ganciclovir has been so effective in treating CMV disease, a variety of mostly ganciclovir-based regimens have been administered for variable periods of time post-transplant to at-risk recipients (i.e. seropositive donor and/or recipient) to try to prevent CMV disease ${ }^{74-79}$. Acyclovir (800 $\mathrm{mg}$ three times daily) from POD 7 to 90 in 11 recipients was compared to a short course of ganciclovir ( $5 \mathrm{mg} / \mathrm{kg}$ twice a day) from POD 5 to 19 , followed by $5 \mathrm{mg} / \mathrm{kg}$ daily from POD 20 to 26, followed by acyclovir $800 \mathrm{mg}$ three times daily until POD 90 in 13 recipients $^{74}$. By 140 days post-transplant the prevalence of CMV illness with acyclovir (91\%) was similar to that of historical controls who received no prophylaxis. The ganciclovir-treated group, however, experienced significantly fewer episodes of CMV illness (38\%) compared to the acyclovir-treated group. In a second study, ganciclovir (as administered in the previous study ${ }^{74}$ ) was compared to a longer course of $5 \mathrm{mg} / \mathrm{kg}$ twice a day from POD 5 to 19 followed by $5 \mathrm{mg} / \mathrm{kg}$ a day until POD $90^{75}$. A significant advantage for the longer course of ganciclovir was observed for up to 1 year posttransplant ( $50 \%$ vs $15 \%$ ). However, when recipients were followed for 2 years post-transplant, no significant differences were observed between shorter and longer durations of ganciclovir prophylaxis due to additional episodes of CMV illness that occurred later in the longer-duration prophylaxis group (58\% vs $42 \%$ ).

The effect of prophylaxis with ganciclovir as assessed by level of risk (defined by donor and recipient pretransplant serologic status for CMV) has also been evaluated ${ }^{76-79}$. The highest-risk group of recipients are those at risk for primary infection (R-D+), and they have received the most intensive prophylaxis regimens (Table 12). The most aggressive regimen has been a 90 -day course of ganciclovir at the University of Pittsburgh. The only effect of this regimen was to significantly delay the onset of CMV illness from a mean and median of 60 and 51 days post-transplant to 135 and 126 days post-transplant, respectively. It did not affect the location or severity of the disease that developed once the prophylaxis was stopped. When the data from all of the prophylaxis regimens from different centers are combined, the prevalence of CMV disease was not significantly different between the group that received some kind of prophylaxis (67\%) compared to the group that received no prophylaxis $(87 \%)$. Hence, no regimen has yet been demonstrated to adequately protect $R-D+$ recipients from CMV disease.

In recipients at risk of CMV reactivation $\left(R_{+}\right)$, the following observations regarding prevalence and effect of prophylaxis can be made from the combined data from several centers ${ }^{76.79}$ (Table 13). The overall prevalence of disease has been $25 \%$, and this was significantly higher in $\mathrm{R}+\mathrm{D}+$ recipients (at $36 \%$ ) compared to $\mathrm{R}+\mathrm{D}-$ recipients (at $20 \%$ ). The prevalence of $\mathrm{CMV}$ disease was: (a) $38 \%$ in the absence of prophylaxis and not significantly different in $\mathrm{R}+\mathrm{D}+$ recipients $(46 \%)$ compared to $\mathrm{R}+\mathrm{D}$ - recipients ( $21 \%)$; (b) significantly lower $(22 \%)$ with any type of prophylaxis compared to those who received no prophylaxis $(38 \%)$; and (c) significantly higher in $\mathrm{R}+\mathrm{D}+$ recipients $(34 \%$ ) compared to $\mathrm{R}+\mathrm{D}-$ recipients $(20 \%)$ despite prophylaxis.

At the University of Pittsburgh the prevalence of CMV disease in the 2 years following completion of a course of prophylaxis was $25 \%$ in $\mathrm{R}+$ recipients who received one of three regimens that contained at least 2 weeks of ganciclovir $(5 \mathrm{mg} / \mathrm{kg}$ twice daily) from POD 7 to 21 . This was not significantly different from the prevalence of $31 \%$ in historical control recipients who received no prophylaxis. Compared to controls, all three regimens modestly decreased the prevalence of CMV disease in $\mathrm{R}+\mathrm{D}+\mathrm{re}-$ cipients, and this achieved statistical significance for the $R+D+$ recipients who received ganciclovir for 90 days post-transplant (10\% vs $63 \%$ ). All regimens except acyclovir for 90 days in $\mathrm{R}+\mathrm{D}$ - recipients significantly $(p<0.05$ by Mann-Whitney) delayed the emergence of CMV illness from a mean and median of 44 and 39 days without prophylaxis to 214 and 154 days posttransplant with prophylaxis, respectively (data not shown). Thus,

Table 12 Prevalence of CMV disease in $\mathrm{R}-\mathrm{D}+$ recipients with different prophylaxis regimens

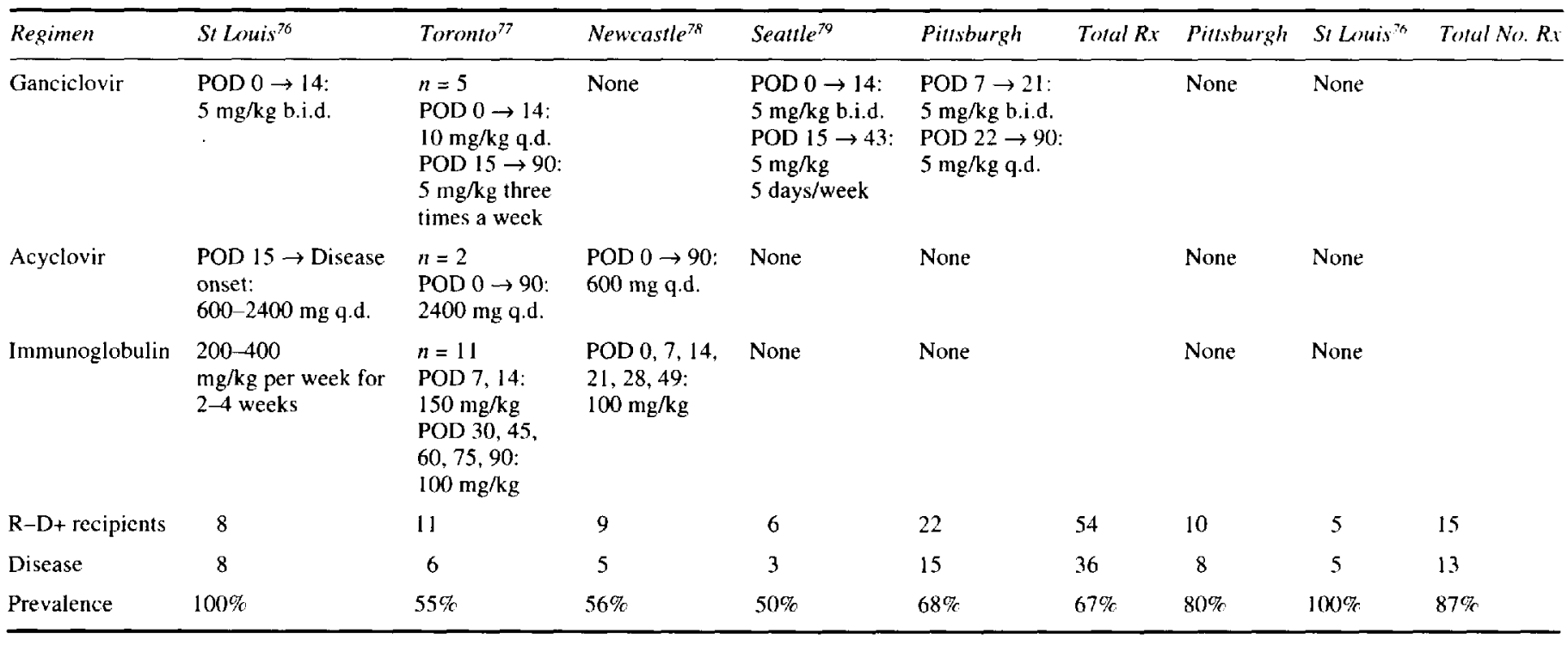


any type of prophylaxis appears to confer some resistance to CMV disease, especially in $\mathrm{R}+\mathrm{D}+$ recipients. These recipients do have a significant risk of CMV disease $(36 \%)$, although it is intermediate to that of $\mathrm{R}-\mathrm{D}+$ recipients $(87 \%)$ and $\mathrm{R}+\mathrm{D}-$ recipients $(20 \%)$. The primary effect of prophylaxis in $\mathrm{R}+$ recipients is to significantly delay the emergence of CMV illness.

In summary, the use of CMV-negative blood products in R-Drecipients is mandatory, and is the only prophylaxis necessary in this group (Table 11). In recipients at risk of reactivation infection $(\mathrm{R}+)$ and especially of primary infection $(\mathrm{R}-\mathrm{D}+)$, no prophylaxis regimen has conclusively demonstrated a benefit in CMV disease prevention. All ganciclovir-based regimens, however, delay the emergence of CMV disease until after the greatest risk of acute rejection has passed. This is beneficial because acute rejection can be treated more aggressively when coexistent or emergent CMV disease is not a concern. Recipients can also cope better with the effects of CMV when they have more fully recovered from the non-specific effects of the transplant procedure (i.e. weakness, fatigue, anorexia, etc.). Ganciclovir as a single agent at a dose of $5 \mathrm{mg} / \mathrm{kg}$ twice a day for 2 weeks followed by $5 \mathrm{mg} / \mathrm{kg}$ a day is remarkably effective at preventing CMV disease as long as it is administered daily. The problem arises when ganciclovir stops. Recently, oral ganciclovir has been demonstrated to be as efficacious as i.v. ganciclovir in preventing progression of CMV retinitis in AIDS patients ${ }^{80}$. Perhaps $\mathrm{R}-\mathrm{D}+$ recipients should receive lifelong prophylaxis with oral ganciclovir.

\section{FUNGAL INFECTION}

The prevalence of fungal infection in lung recipients has been $15 \%$ at Stanford University ${ }^{81}, 13 \%$ at the University of Toronto? and $22 \%$ at Loyola University ${ }^{\$ 2}$. At the University of Pittsburgh the prevalence of fungal infection has been $19 \%$, with 68 infections caused by 71 fungal organisms in 359 allografts in 350 recipients who survived $\geqslant 14$ days post-transplant (Tables 14 and 15). Three infections have been due to two different types of fungi. A little more than one-third (38\%) of these infections have been due to Candida species, and nearly half (45\%) have been due to species of Aspergillus. Fungal infection has accounted for $6 \%(68 / 1173)$ of all infectious complications and has been equally likely to occur within the first year or $>1$ year post-transplant (Table 4). It has caused the failure of 22 allografts (11\%); 14 failures $(64 \%)$ occurred within the first year post-transplant (Table 2). These infections have occurred as early as 6 days and as late as 2917 days (6.5 years) post-transplant. As the median occurrence is only 52 days post-transplant, the majority of these infections have occurred early after transplantation.

\section{Prevalence}

The prevalence of fungal infection before the availability of fluconazole, itraconazole, or aerosol amphotericin for prophylaxis was $20 \%$ (with 37 infections in 185 at-risk recipients) (Table 15).

Table 13 Prevalence of $\mathrm{CMV}$ disease in $\mathrm{R}+$ recipients with different prophylaxis regimens

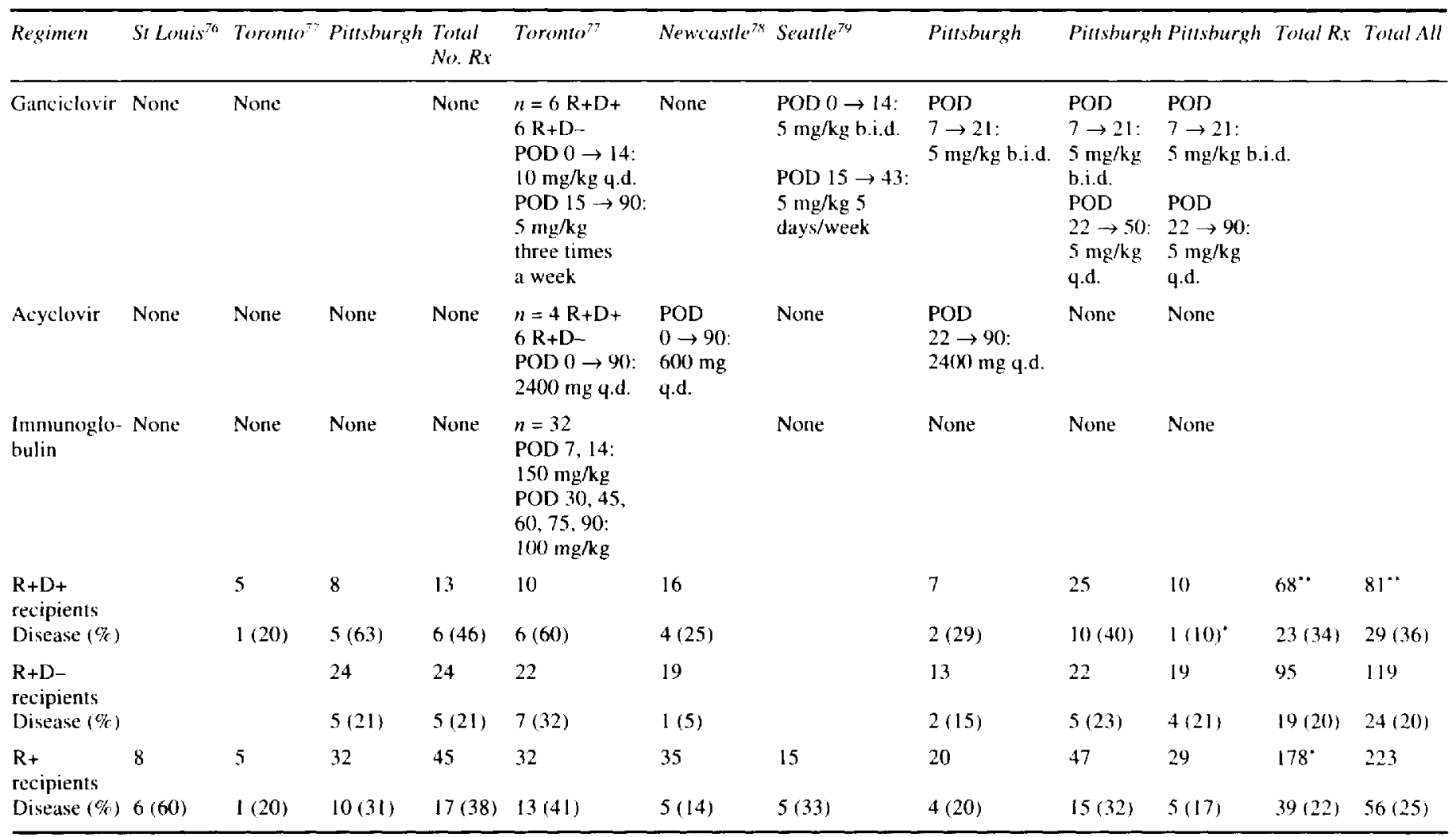

" $p<0.05$ compared to none by chi-square.

" $p<0.05$ compared to $\mathrm{R}+\mathrm{D}$ - recipients by chi- quare. 
Table 14 Etiologic agents and time of occurrence of fungal infections after lung transplantation at the University of Pittsburgh

\begin{tabular}{lc}
\hline & $n(\%)$ \\
\hline Etiologic isolates & \\
$\quad$ Candida species & $27(38)$ \\
Aspergillus species & $32(45)$ \\
Mucor & 1 \\
Cryptococcus & 1 \\
Phialophora repens & 1 \\
Pseudallescheria specics & 4 \\
Torulopsis & 3 \\
Trichophytin & 1 \\
Dactylaria gallopava & 1 \\
$\quad$ Total & 71 \\
Time of occurrence in daws post-transplam & \\
Mean \pm 1 SD & $371 \pm 695$ \\
Median & 52 \\
Range & $6-2917$ \\
\hline
\end{tabular}

Table 15 Prevalence, site and mortality of fungus infections with or without prophylaxis at the University of Pittsburgh

\begin{tabular}{lccc}
\hline & \multicolumn{2}{c}{ Prophylaxis } & Tolal (\%) \\
\hline No(\%) & Yes (\%) \\
\hline Recipients & 185 & 165 & 350 \\
Infection sites & & & \\
$\quad$ Disseminated & $13(35)$ & $1(3)^{*}$ & 14 \\
Lung & 13 & 10 & 23 \\
Airway & 3 & 9 & 12 \\
GI & 0 & 2 & 2 \\
Brain & 0 & 3 & 3 \\
Skin incision & 1 & 1 & 2 \\
Mediastinum & 1 & 1 & 2 \\
Pleura & 2 & 2 & 4 \\
Aorta, pulmonary artery anastomosis & 3 & 0 & 3 \\
Skin & 0 & 1 & 1 \\
Breast & 0 & 1 & 1 \\
Blood & 1 & 0 & 1 \\
& $37(20)$ & $31(19)$ & $68(19)$ \\
Mortality & $18(10)$ & $7(4)^{*}$ & $25(7)$ \\
\hline
\end{tabular}

- $p<0.05$ compared to no prophylaxis by chi-square.

All of these infections, except one episode of septicemia and one infection in an incision, originated in the allograft. By the time of diagnosis, $35 \%$ of these infections had disseminated to other body sites, particularly within the thorax, such as the mediastinum (one), pleural space (two) and aortic anastomosis (three) ${ }^{83}$. Fungal infection was highly lethal (49\% mortality). Eleven $(30 \%)$ of these infections were recognized only at autopsy.

\section{'Prophylaxis' and treatment}

It was noted, however, that the fungus culture of respiratory tract secretions (sputum or BAL) obtained within 2 weeks before a diagnosis of a fungal infection was always positive whenever true infection was present $(n=8)$, and was always negative when infection was absent (Table 16). Because of this observation, any fungal isolate from respiratory tract secretions has since been promptly treated with anti-fungal agents. If a culture from the airways of the donor or recipient contains Candida. fluconazole ( $400 \mathrm{mg}$ orally or i.v. daily) has been administered until 4 weeks have elapsed since the last positive culture. If Aspergillus has been recovered, aerosol amphotericin (5-15 mg three times daily) and/or oral itraconazole (400-600 mg daily) have been administered. When the itraconazole blood level drawn 2-4 hours after a dose had risen $\geqslant 8 \mu \mathrm{g} / \mathrm{ml}$, which was usually within 7-10 days, the amphotericin was usually discontinued. Itraconazole is continued for 6-12 months after the last positive culture. When the risk of Aspergillus infection was high (i.e. symptoms present, abnormal chest radiograph. $\angle$ POD 90 or chronic rejection present) or it was not possible to use itraconazole, these isolates have additionally usually been treated with i.v. amphotericin $(<0.6 \mathrm{mg} / \mathrm{kg}$ per day) until the itraconazole blood level was therapeutic and/or the clinical outcome was improving.

Since the introduction of this regimen, 31 infections due to 31 fungal isolates have occurred in 165 at-risk recipients for a prevalence of $19 \%$ (Table 15). The majority of these infections (68\%) originated in the allograft, all but one infection was detected antemortem, and only one infection (3\%) disseminated to other body sites by the time of diagnosis. Seven (23\%) were fatal. The nine airway infections included five episodes of ulcerative tracheobronchitis due to Aspergillus, and all were treated successfully ${ }^{81}$.

As compared to the era before prophylaxis, the prevalence of fungal infections has not changed ( $20 \%$ vs $19 \%$ ), but the likelihood of dissemination has decreased significantly from $35 \%$ to $3 \%$, and the risk of death has decreased significantly from $10 \%$ to $4 \%$. This is particularly significant since the frequency of isolation of fungal organisms from the respiratory tract has increased, most probably due to the increasing use of 'prophylactic' antibacterial antibiotics. Treating all fungal isolates from the allograft has resulted in many instances of treating contaminants, insignificant infection, and/or 'colonization' because the predictive value of a positive culture was only $16 \%$ (Table 16). Nevertheless, this approach appears to be justifiable because the mortality from this infection has decreased significantly, and this is most likely a consequence of this intervention.

\section{Relationship with obliterative bronchiolitis (chronic rejection)}

Just as with bacterial pneumonia and bronchitis that occur late after transplantation (Table 7), there also appears to be a relationship between late fungal infection in the allograft and chronic allograft rejection (Table 17). Luckily, only $8 \%$ of the recipients

Table 16 Reliability of a fungus culture of respiratory secretions to detect fungus infections in lung recipients at the University of Pittsburgh in the pre-prophylaxis era

\begin{tabular}{lcc}
\hline & \multicolumn{2}{c}{ Infection } \\
\cline { 2 - 3 } Culture & Present & Absent \\
\hline Positive & 8 & 41 \\
Negative & 0 & 398 \\
\hline Sensitivity & $100 \%$ & \\
Specificity & $92 \%$ & \\
Positive predictive value & $16 \%$ & \\
Negative predictive value & $100 \%$ & \\
\hline
\end{tabular}


Table 17 Relationship of fungal infection in the allograft to chronic rejection $(\mathrm{CR})$ in recipients who survived $>90$ days or $>2$ years post-transplant at the University of Pittsburgh

\begin{tabular}{lcc}
\hline Fungus infection & \multicolumn{2}{c}{ Episodefrecipient } \\
\cline { 2 - 3 } & Surnival $>90$ dorss & Survival $>2$ vears \\
\hline CR+ & $16 / 107=0.15$ & $6 / 78=0.08$ \\
CR- & $8 / 1.34=0.04$ & $2 / 75=0.03$ \\
\cline { 2 - 2 } Total & $24 / 291=0.08$ & $8 / 155=0.05$ \\
\hline
\end{tabular}

who survived $>90$ days and $5 \%$ of the recipients who survived $>2$ years have developed fungus infection in the allograft. However, $66 \%$ of the fungal infections that developed $>90$ days post-transplant and $75 \%$ of those that developed $>2$ years post-transplant occurred in recipients with $O B$. The infection rate was three to four times greater in recipients with $\mathrm{OB}(0.08-0.15$ for $\mathrm{OB}+$ versus $0.03-0.04$ for $\mathrm{OB}-$ recipients). This relationship between $O B$ and increased risk of fungal infection may be due to: (a) a direct effect of an inability of airways damaged by $O B$ to clear inhaled fungal spores, (b) an indirect effect of the increased use of antibacterial antibiotics used to treat the airway bacterial infection that is also associated with $\mathrm{OB}$, or (c) the use of augmented immunosuppression to treat $\mathrm{OB}$. Thus, any fungal infection in the allograft $>90$ days post-transplant should raise a suspicion that $\mathrm{OB}$ is also present.

\section{PNEUMOCYSTIS INFECTION}

The overall prevalence of this infection in patients who survived $>2$ weeks post-LTx has been low at $8 \%$ (Table 18). Its prevalence before prophylaxis was employed was $71 \%^{84}$. Its prevalence with prophylaxis with either (a) one single-strength trimethoprimsulfamethoxazole tablet twice or three times per week or (b) dapsone $100 \mathrm{mg}$ orally three times per week for recipients who are allergic to or intolerant of sulfonamides has decreased significantly to $4 \%$. An episode of infection has almost always been associated with non-compliance with prophylaxis.

The majority $(69 \%)$ of these infections have been detected by surveillance BAL procedures in asymptomatic recipients. Clinical pneumonia occurred in seven cases $(20 \%)$, and the infection was subclinical in four $(11 \%)$. This infection has occurred as early as POD 13 and at any time thereafter. With mean and median occurrences of 433 and 166 days post-transplant, respectively, most infections $(n=25)$ have occurred within the first year posttransplant.

Table 18 Prevalence of Pneumocystis (PCP) infection with and without prophylaxis after lung transplantation at the University of Pittsburgh

\begin{tabular}{llcc}
\hline & \multicolumn{3}{c}{ Prophylaxis } \\
\cline { 2 - 4 } & No & Yes & Total \\
\hline Recipients at risk & 21 & 338 & 359 \\
Recipients with PCP & $15(71 \%)$ & $14(4 \%)^{*}$ & $29(8 \%)$ \\
Infections & 19 & 16 & 35 \\
\hline
\end{tabular}

$p<0.6001$ compared to no prophylaxis by chi-square

\section{EPSTEIN-BARR VIRUS (EBV)-INDUCED LYMPHOPROLIFERATIVE DISEASE (PTLD)}

The prevalence of this infection has been $4 \%$ at Papworth Hospital with three infections in 67 heart-lung transplant recipients $^{85}$. It has been $7 \%$ at the University of Pittsburgh with 22 infections in 325 recipients who survived $>30$ days posttransplant ${ }^{86-8 x}$. Eleven episodes $(50 \%)$ occurred 43-120 days post-transplant and $17(77 \%)$ within the first year. Five recipients developed PTLD after the first year. Where serology for EBV from both donor and recipient was available, six infections occurred in $\mathrm{R}-\mathrm{D}+$ recipients $(27 \%)$, two infections occurred in $\mathrm{R}+\mathrm{D}+$ recipients $(9 \%)$, and one infection occurred on POD 554 in a $\mathrm{R}-\mathrm{D}-$ recipient. Three $\mathrm{R}-\mathrm{D}+$ recipients have never developed PTLD. The initial site of involvement was the allograft in 16 (73\%) recipients, lymph nodes in two recipients, the gastrointestinal tract in three, and the brain in one. PTLD disseminated to multiple organs in six recipients.

The first affected recipient was treated with chemotherapy and died 45 days later from bacterial sepsis from a bowel perforation secondary to a regressing focus of PTLD. The autopsy revealed persistent disseminated PTLD and disseminated Cryptococcus infection. The initial treatment for all other affected recipients has been a major reduction in immunosuppression (by withdrawal of corticosteroids and azathioprine and an approximate $75 \%$ reduction in the dose of cyclosporin or tacrolimus) until clear evidence of regression was present ${ }^{89}$. Thirteen patients $(59 \%)$ achieved a remission of all clinically evident disease although, of these, one subsequently developed recurrent PTLD, one died of bacterial pneumonia, and six developed $\mathrm{OB}$ which was fatal in four. Thus, there are five remaining recipients $(24 \%)$ treated only with a temporary reduction in immune suppression, who are without PTLD or other complications.

The PTLD did not remit with decreased immunosuppression in eight recipients. One received no further therapy and died of bacterial pneumonia and disseminated PTLD. A second died immediately after retransplantation. Three were treated with alphainterferon ${ }^{90}$. The PTLD remitted in two, but one of these developed severe acute rejection which necessitated retransplantation, and $O B$ developed in the second allograft. One recipient did not respond to alpha-interferon and was retransplanted without further sequelae. Three recipients received radiotherapy for what was thought to be localized disease. These died from (a) disseminated PTLD and bacterial sepsis, (b) disseminated Aspergillus infection after chemotherapy for disseminated PTLD (PTLD was not found at autopsy), and (c) OB (PTLD was localized and did remit after radiation therapy) respectively. Overall, the mortality has been $50 \%$ but that due directly to PTLD has been $23 \%$.

Thus, PTLD occurs in about $4-7 \%$ of LTx recipients usually (a) in the first 120 days post-transplant, (b) in recipients at risk of primary infection, and (c) with the allograft being the initial site of involvement. While remission can be achieved in most with decreased immunosuppression alone, morbidity and mortality are significant.

\section{OTHER VIRUSES}

Lung recipients are at risk for significant infection with herpes simplex virus (HSV). The prevalence of this infection at 
Papworth Hospital has been $18 \%$ with six episodes of pneumonitis, one of which was fatal ${ }^{91}$. However, acyclovir effectively prevents serious HSV infection. At the University of Pittsburgh no HSV infections have occurred in seronegative recipients who received an allograft from a seropositive donor (R-D+) when treated with acyclovir ( $400 \mathrm{mg}$ orally three times daily for the first 3 months). Some episodes of mucocutaneous infection due to HSV have occurred after prophylaxis has stopped.

At the University of Minnesota the prevalence of infection with the paramyxoviruses, parainfluenza (PIV), and respiratory syncytial virus (RSV), has been $21 \%$, with 19 infections in 18 of 85 atrisk recipients ${ }^{92}$. All were associated with signs and symptoms of lower respiratory tract involvement, and nine were also associated with signs and symptoms of upper respiratory tract infection. Nine infections (11\%) were due to RSV. Only one RSV infection was associated with a transient but significant decline in spirometry, and one untreated RSV infection was fatal. RSV infections were seasonal - all occurred between January and June with the peak incidence in February. Ten infections (12\%) were due to PIV, five of which were associated with a significant decline in spirometry. There was no seasonality associated with this infection. Fourteen infections were treated with ribavirin, which was tolerated by all and efficacious in most patients.

A few episodes of infection due to adenovirus, influenza, and Coxsackie virus ${ }^{9.3}$ have been reported. At the University of Pittsburgh, four of five infections with adenovirus were fatal. All other infections of these types have resolved without specific treatment.

\section{MYCOBACTERIA}

Candidates for LTx should receive intradermal skin tests to PPD, Candida and mumps, but the appropriate response to a positive PPD pretransplant is not clear. The practice at the University of Pittsburgh has been to treat those who react to PPD with isoniazid (INH) for 1 year before and 1 year after LTx. Infections due to Mycobacterium tuberculosis have been rare at all centers. Only eight cases have been reported ${ }^{9+-96}$ and all have involved the allograft between 2 and 20 months post-transplantation. Infections isolated to the allograft have all been treated successfully, but two disseminated infections were fatal. The prevalence of $M$. tuberculosis infection at the University of Pittsburgh has been $<1 \%$, with only one infection in 299 recipients who survived $>60$ days posttransplant. This single episode occurred in a single-lung recipient who developed pulmonary and pleural tuberculosis from a pansensitive isolate 64 days post-transplant, while receiving INH prophylaxis for a positive pretransplant intradermal PPD skin test. The diagnosis was made by recovery of the organism in two sequential BAL specimens separated in time by 2 months. Remission was achieved by eliminating azathioprine, lowering the doses of corticosteroids and tacrolimus, and treating the infection with INH, pyrazinamide (PZA), and ethambutol for 1 year. (Rifampin was not used, because of the difficulty of maintaining adequate blood levels of cyclosporin or tacrolimus with its concurrent use.) Remission has continued for $>1$ year without antituberculosis therapy. One further double-lung recipient with unsuspected $M$. tuberculosis in the native lungs had no recurrence post-transplant after treatment with INH and PZA (for 4 months) followed by INH and ethambutol (for 8 additional months).
Atypical mycobacteria have been isolated in several instances from $\mathrm{BAL}$ specimens in asymptomatic recipients at the University of Pittsburgh. Treatment has been withheld and no recipient has developed disease. $M$. chelonae infection, however, has occurred in a heart-lung recipient about 6 months post-transplant ${ }^{97}$. This recipient developed OB 2 months after the organism was isolated, and died 2 months later from $O B$ and persistence of infection, despite the aggressive use of appropriate antibiotics. Thus, infection with atypical mycobacteria is a rare but possible event.

\section{INFECTION IN THE NATIVE LUNG}

After single LTx a diseased native lung is left in proximity to the allograft. When this lung becomes infected, the infection can be transmitted to the allograft or systemically. Infections in the remaining native lung due to Pseudomonas, Nocardia and especially Aspergillus have occurred and some have been transmitted to the allograft. The principles of treatment of these infections include a reduction in immunosuppression, administration of appropriate antibacterial or antifungal therapy, and consideration of surgical resection of the infected native lung 98.99 . With the increasing popularity of single LTx, infection arising in the native lung and transmitted to the allograft will be a more frequent occurrence.

\section{INFECTION TRANSMITTED FROM THE DONOR LUNG}

The observation that the presence of bacteria in the airways of the donor lung at the time of transplantation was significantly associated with early bacterial infection in the allograft led to the concept that the donor could transmit infection to the recipient ${ }^{15}$. This was subsequently demonstrated in a canine model ${ }^{16}$. While inocula into the lung of $10^{4}$ colony-forming units (cfu) of Streptococcus pneumoniae did not cause pneumonia in normal or even immunosuppressed dogs, inocula of only $10^{2} \mathrm{cfu}$ given to donors resulted in pneumonia in all recipients. Thus, a minimally infected donor lung appears to be very susceptible to the subsequent development of bacterial pneumonia in the immunosuppressed recipient. In the canine model, treatment of infected donors with antibiotics prevented pneumonia from occurring in the recipients. In the human situation, broad-spectrum antibiotics are begun preoperatiyely and adjusted postoperatively according to the results of cultures taken from the airways of the donor at the time of transplantation. This is the most likely reason for the marked decrease in the prevalence of early bacterial pneumonia at the University of Pittsburgh (Table 6) and for the low rate of early infection at Papworth Hospital, where only two of 19 early infections in 125 heart-lung recipients $(2 \%)$ were felt to be donoracquired ${ }^{100}$. It is also suspected that fungi in the airways of the donor carry a high risk of causing fungal infection in the recipient. Hence, such isolates are commonly 'prophylactically' treated.

In this era where CMV-negative blood products are employed with any seronegative recipient $(\mathrm{R}-)$, it is evident that allografts from CMV-seropositive donors ( $\mathrm{D}+$ ) very effectively transmit CMV disease to the recipient (Table 12). In fact, prevention of this transfer from the donor is a challenge yet to be solved. It also appears that the majority of the episodes of EBV-induced PTLD 
that occur as a consequence of primary infection result from transmission of EBV virus from the donor lung to the recipient. Preventing or ameliorating this transfer is another challenge for the future. As has been demonstrated for tuberculosis ${ }^{94}$, the donor is probably capable of transmitting any type of infection to the recipient, including hepatitis $\mathrm{C}$ and the human immunodeficiency virus $^{101-103}$.

\section{COMMENT}

Although infection as a cause of morbidity (Table 3 ) and mortality (Table 1 ) has decreased significantly, it remains the primary cause of morbidity and mortality after LTx. The advances that are responsible for the decline in the toll exacted by infection include the use of: (a) antibacterial and antifungal agents to treat organisms in the airway of the donor at the time of transplantation and when $\mathrm{OB}$ is present, (b) CMV-negative blood products when the donor and recipient are seronegative (R-D-), (c) ganciclovir to treat CMV disease, (d) ganciclovir for at least 2 weeks posttransplant when the recipient is seropositive $(\mathrm{R}+)$, (e) antifungal agents when fungi are recovered from the allograft, (f) trimethoprim-sulfamethoxazole or other agents to prevent Pneumocystis infection, (g) frequent bronchoscopy with BAL and TBBx to assess the allograft ${ }^{17.3 .}$, and (h) fewer empiric pulses of augmented immunosuppression to treat clinical rejection. The improvement in survival after LTx over the past decade has been largely due to the advances made in the control of infection.

Challenges still remain! As the current trend is of increasing immunosuppression to try to prevent or ameliorate acute rejection. and thus try to prevent the subsequent development of $\mathrm{OB}^{72}$. our challenge will be to prevent an upsurge in post-transplant infections. The optimum regimens (a) to prevent and treat bacterial and fungal infections, (b) to prevent CMV disease in R-D+ recipients, and (c) to prevent EBV-induced PTLD are still to be discovered. The current approach of treating so many bacterial and fungal isolates is not cost-effective in today's environment of cost containment, and may well promote the development of antibiotic resistance. Thus, although much has been accomplished, much remains to be done to minimize the morbidity and mortality related to infection after lung transplantation.

\section{References}

1. Dauber HH, Paradis Il, Dummer JS. Infectious complications in pulmonary allogratt recipients. In: Grossman R. Maurer J. editors. Pulmonary consideration in transplantation clinics in chest medicinc. Philadelphia, PA: Saunders; 1980;22:291.

2. Maurer JR. Tullis E. Grossman Rf et ad. Infectious complications following isolated lung transplantation. Chest. 1992:101:1056.

3. Paradis IL. Williams P. Infections alter lung transplantation. In: Sarosi GA. Trulock EP. cditors. Infectious complications of transplantation. Seminars in respiratory infection. Philadelphia. PA: Saunders: 1993:8:207.

4. Dummer IS. Hardy A. Poorsatlar A. Ho M. Early intections in kidney, heart and liver trunsplant recipients on cyclosporin. Transplantation. 1983:36:259.

5. Dummer JS, Montero CG. Paradis IL et al. Infections in heart-lung transplant recipients. Transplantation. 1986:41:725.

6. Hotflin JM, Potasman I. Baldwin JC et al. Infectious complications in heart transplan recipients receiving cyclosporin and corticosteroids. Ann lntern Med. 1987:106:209.

7. Brooks RG. Hofflin JM, Jamieson SW, Stinson EB, Remington JS. Infectious complications in heart-lung transplant recipients. Am J Med. 1985:79:412.

8. Hosenpud JD, Hershberger RE, Pantely GA et al. Late infection in cardiac allograft recipients: protiles, incidence and outcome. J Heart Lung Transplant. $1991 ; 10: 380$.
9. Mancini MC, Griffith BP. Tauxe WN. Astessunent of ciliary function in the tracheobronchial tree of the heart-lung transplant recipient. Surg Forum 1987;38:300.

10. Dolovich $M$. and the Toronto Lung Transplant Group. Muco-ciliary function in patients following single lung or lung hean transplantation. Am Rev Respir Dis. 1987:135:A363.

11. Shankar S, Fulsham L. Read RC ef al. Mucociliary lunction after fung tramsplantidtion. Transplant Proc. 1991:23:1222.

12. Read RC, Shankar $S$, Rutman $A$ et al. Ciliary beat frequency and structure of recipient and donor epithelia following lung transplantation. Eur Respir J. 1991:4:796.

13. Herve $P$ and the Paris-Sud Lung Transplant Group. Impairment of bronchial mucociliary clearance in long-lerm survivors of heart-lung and double-lung transplantation. Chest. 1993;103,59.

14. Paradis IL, Marrari M. Zeevi A ef al. HLA phenotype of lung lavige cells following heart-lung transplantation. J Heart Transplant. 1985;4:422.

15. Zenati M, Dowling RD. Dummer JS ef al. Inlluence of donor lung on the development of early infections in heart-lung transplant recipients. J I leart Transplant. 1990):5:5012

16. Dowling RD, Zinati M, Yousem SA $e^{\prime}$ al. Donor-transmitted pneumonia in experimental lung allografts. Successful prevention with donor antibiotic therapy. J Thorac Cardiovalsc Surg. 1992;103:767

17. Guilinger RA. Paradis IL. Dauber JH et al. The inportance of bronchensonpy with transbronchial biopsy and bronchoalveolar lavage in the management of lung trausplant recipients. Am J Respir Crit Care Med. 1995:152:21131.

18. Martinez JAB, Paradis IL, Dauber JH et al. Spirumetry values in stable lung transplant recipients. Am J Respir Cril Care Med (ln press).

19. Thorpe JE, Baughman RP, firame PT, Wexseler TA. Stancek JI. Brenchoalveolar lavage for diagnosing acute bacterial pneumonia. J Infect Dis. 1987:155:855.

20. Kahn $\mathrm{HW}$, Jones JM. Diagnosing bacterial infection by bronchoalveclar lavage. J Intect Dis. 1987:155:862.

21. Chastre J. Fagon JY. Soler P et al. Diagnosis of noxecomial pneumonia in intehated patients undergoing ventilation: comparison of the usefulness of bronchoalveolar lavage and the protected specimen brush. Am J Med. 1988:85 499.

22. Johanson WG. Seidenfeld JJ. Gomez P. de los Santos R. Coalson JJ. Bacteriolagic diagnosis of nosocomial poxumonia following profonged mech inical ventilation. Am J Respir Dis. 1988:137:259.

23. Torres A, de la Bellacasa JP, Xaubert $A$ el al. Diagnostic value of yuantitative cultures of bronchoalveolar lavage and telescoping plugaged catheters in mechanically ventilated patients with bacterial pneumonia. Am Rev Rexpir Dis. 1989: 140:306.

24. Meduri GU, Chastre J. The standardization of bronchoverpie techniques for venti Jation-dssociated pneumonia. (he $+1992: 102: 557 \mathrm{~S}$

25. Chastre J. Fagon JY. Soler P. de d. Quantitation of BAL ecells comtaining intracel lular bacteria rapidly identifies ventilated patients with nosocomial pneumonia Chest. 1989:95:1905.

26. Neiderman MS, Torres A. Summer $W$. Invasive diagnestic testing is not needed reutinely to manage suspected ventilator-associated pneumonia. Am J Respir Crit Care Med. 1994:150:565.

27. Chastre J, Fagon JY. Invasive diagnostic testing should be roucinely used to manige ventilated patients with suspected pneumonia. Am J Respir (rit Care Med. $1994 ; 150: 570$

28. Marquette CH. Copin MC. Wallet F et al. Diagnostic tests for pneumonia in ventilated patients: prospective evaluation of diagnostic atcuracy using histology as a diagnestic gold standard. Am J Respir Cril Care Med. 1995;151:1878.

29. Chastre J, Fagon JY. Bornel-1.ecso $M$ at al. Fvaluation of bronchoscopic technicyues for the diagnosis of nosocomial pneumonia. Am J Respir ('ril Care Med. 1995:152:231.

30. Stuver DE, Zaman MB, Hajdu Sl et al. Bronchoralveolar lavage in the diagnosis of diffuse pulmonary infiltrates in the immunosuppresised host. Ann Intern Med 1984:101:1.

31. Broaddus C, Dake MD. Stulbarg MS al al. Bronchoalveolar lavage and transbronchial lung biopsy for the diagnosis of pulmonary infections in the asquired immunodeficiency syndrome. Ann Inlern Med. 1985:102:747.

32. Pisani RJ. Wright AJ. Clinical utility of bronchoalveolar lavage in immunocompromised hosts. Mayo Clin Proc. 1992:67:221.

33. Higenboltam T. Stcwarl S, Penketh $A$, Wallwork J. Transbronchial lung biopsy for the diagnosis of rejection in heart--Iung transplant patients. Transplantalion. 1988:46:532.

34. Yousem SA, Paradis II., Dauber JH. Griftith GP. Efticacy of transbronchial lung biopsy in the diagnosis of bronchiolitis obliterans in heart-lung transplant recipients. Transplantation. 1989;47:893.

35. Yousem SA, Paradis IL. Griftith BP. Can transbronchial lung hiopsy aid in the diagnosis of bronchiolitis obliterans in lung transplant recipients? Transplantation 1994:57:151.

36. Paradis IL, Duncan SR, Dauber JH et al. Distinguishing between infection, rejection and the adult respiratory distress syndrome after human lung transplantation. J Heart Lung Transplant. 1992:11:232S.

37. Paradis I, Yousem S. Griffith B. Airway obstruction and bronchiolitis obliteran after lung transplantation. In: King TE, editor. Clinics in chest medicine Philadelphia, PA: Saunders: 1993:24:751.

38. Maurer JR. Lung transplantation bronchiolitis obliterans. In: Epler GR, editor Diseases of the bronchioles. New York: Raven Press: 1994:275. 
39. Snell Gl. de Hoyas A. Krajden M. Winton T. Maurer JR. Pseudomonas ceparid in lung transplant recipicints with cystic fibrosis. Chest. 1993;103:466.

40. Lewiston N, King V, Umetsu D et al. Cystic fibrosis patients who have undergone heart-lung transplantation benefit from maxillary sinus antrostomy and repeat sinus lavage. Transplant Proc. 1991:23:1207.

41. McGowan JE. Anti-microbial resistance in hospital organisms ind its relation tw antibiotic use. Rev Infect Dis. 1983:5:10133

42. Sanders WE, Sanders CC. Inducible $\beta$-lactamases: clinical and epidemiologic implications fir use of newer cephalesporins. Rev Infect Dis. 1988:10:830.

43. Pelerson LP. Quick JN, Jensen B at al. Emergence of ciprofloxacin resistance in nosocomial methicillin-resistant $S$. aureus colonization. Arch Intern Med. 1990):150:2151

44. Trucksis M. Hooper I)C. Wolfson JS. Emerging resistance to fluoroquinolenes in staphylococci: an alert. (F.ditorial) Ann Intern Med. 1991:114:424.

45. Chow JW. Fine MI. Shales DM et al. Enternbater hacteremia: clinical features and emergence of antibiotic resistance during therapy. Ann Intern Med. 1991:115:585.

46. Neu HC. The crisis in antibiotic resistance. Science. 1992:257:1064

47. Kunin CM. Resistance to anti-microbial drugs. A worldwide calamity. Ann Intern Med. 1993:118:557.

48. Meyer KS, Urban C. Eagan JA, Berger BJ. Rithal JJ. Nosocomial outbreak of Klebsiella infection resistant to late-genteration cephalosporins. Ann Intern Med. 1993:119:353

49. Pear SM, Williamson TH, Bettin KM, Gerding DN, Galgiani JN. Decrease in nosocomial Clostridium difficile-associated diarrhea by restricting clindamycin use, Ann Intern Mod. 1994;120:272.

50. Weller TH. The cytomegalosirus: ubiquitous agents with protean clinical findings. N Engl J Med. 1971:285:203. 267.

51. Dummer JS. White LT. Ho M at al. Morbidity of cylomegalovirus infection in recipients of heart or heart-lung transplants who received cyclosporin. J Infect Dis, 1985:152:1182.

52. Burke CM, Glanville AR. Macoviak JA at al. The spectrum of cytomegalovirus infeclion following human heart- lung tramsplantation. J Hearl Transplant. 1986:5:267.

53. Duncan AJ. Dummer IS. Paradis IL e't al. Cytomegalowirus infection and survival in pulmonary transplant recipients. J Hear Lung Transplant. 1991:10:638.

54. Maurer J. Tullis E. Scavuzro M. Patterson GA. Cytomegalovirus infection in isolated lung transplant recipients. J Heart Lung Transplant, 1991:10:647.

55. Smyth RL. Scoll JP. Borysiewico LK " al. Cytomegalovirus infection in hear-lung transplant recipients: risk factors. clinical associations and response to treatment. J Infect Dis. 1991: 1 64:1045

56. Duncan SR, Paradis Il. Yousem SA 2 al. Sequelie of cylomegalovirus pulmonary infections in lung allograft recipients. Am Rev Respir Dis. 1992:146:1419.

57. Ettinger NA. Bailey TC. Trulock EP at al. Cytumegalovirus infection and pneumonitis. Impact alfer jsolated lung transplantation. Am Rev Respir Dis. $1993 ; 147: 1017$

58. Zeevi A. Uknis ME. Spichty KJ et al. Proliferation of cytomegalovirus primed Iymphocytes in bronchoalveolar lavage from lung transplant patients. Transplantation. 1992:54:635.

59. Gleaves CA, Smith TF, Shuster EA, Pearson GR. Comparison of standard lube and shell vial cell culture lechniques for the detection of eylomegalovirus in clinical specimens. J Clin Microbiol. 1985:21:217

60. Paya CV. Wold AD. Smith TF. Detection of cytomegalovirus infections in specimens other than urine by the shell vial assay and conventional tube cell cultures. I Clin Microbiol. 1987;25:755.

61. Paradis II, Grgurich WF, Dummer JS, Dekker A, Dauber JII. Rapid detection of cytomegalovirus pneumonia from lung lavage cells. Am Rev Respir Dis. 1988:138:697.

62. Crawtord SW, Bowden RA, Hackman RC at al. Rapid detection of cytomegalovirus pulmonary infection by bronchoalveolar lavage and centrifugation culture. Ann Intern Med. 1988:108:180.

63. Emanuel D. Peppard J. Stover D et al. Rapid immunodiagnosis of cytomegalovirus pneumonia by bronchsalveolar lavage using human and murine monoclonal antibexdies. Ann Intern Med. 1986:104:476

64. van der Bij W, Schirm J. Torensma Ret al. Comparison belween siremia and antigenemia for detection of cytomegalovirus in bleod. J Clin Microbiol. 1988:26:2531

65. Gerra (i, Revello MG, Percivalle E at al. Quantification of human cy tomegalovirus viremia by using monoclonal antihxdies to different viral protcins. J Clin Microbiol. 1990);28:2681

66. Ho M. Cytomeyalovirus: biology and infection. Ncw York: Plenum; 1991

67. Erice A. Holm MA. Gill PC er al. Cytomegatowirus (CMV) antigenemia assay is more sensitive than shell vial cultures for rapid detection of $\mathrm{CMV}$ in polymorphonuclear blood lcukocytes. J Clin Microbiol. 1992;30:2822.

68. Cussol SA, Poon MC. Pal R et al. Primer-mediated cnzymatic amplification of $\mathrm{cy}$ tomegalovirus (CMV) DNA. Applicution to the early diagnosis of CMV infection in marrow transplant recipients. J Clin Invest. 1989:83:1 109.

69. Jiwa NM. Gemen GW. Raap AK et al. Rapid detection of human cylomegalovirus DNA in peripheral bleod leukocytes of viremic transplant recipients by the polymerase chain reaction. Transplantation. 1989:48:72.
70. vonWillebrand E, Pettersson E. Ahouen J. Hayry P. CMV intection. Class II antigen expression. and human kidney allegraft rejection. Transplantition. 1986:42:364

71. Khoury E. Pereira L, Greenspan F:S. Induction of HLA-IDR expression on thyroid follicular cells by cytomegalovirus infection in vitre. An J Pathol. 1991:138:12099.

72. Bando K. Paradis IL. Konishi $\mathrm{H}$ er al. Obliterative bromchiolitis after lung and heart-lung transplantationt: An analysis of risk tactors and manigement. J Thorate Cardiovase Surt. 1995:110:1.

73. Geist IJ, Monick MM. Stinski MF. Hunninghake (iW. Cytomegalovirus immediate early genes prevent the inhibilory effect of eyclosporin $A$ on interleukin 2 gene expression. J Clin Invest. 1992:90):21.36.

74. Duncan SR. Paradis IL. Dauber JII a al. Ganciclovir prophylaxis for cytomegalovirus infections in pulmonary allograft recipiemts. Am Ror Respir Dis. 1992:146:1213.

75. Duncan SR. Gruarich WF. Lacono AT et al. A comparison of ganciclovir and acy. clovir to prevent cylomegalovirus after lung transplantation. Am J Respir Crit Care Med. 1944:150:146.

76. Bailey TC. Trulock EP. Fitinger NA et al. Failure of prophylactic zanciclowir to prevent cytomegalovirus disease in recipients of lung tramsplants. J Infect Dis. $1991: 165: 548$

77. Maurer JR, Snedl G. de Hoyos A. Kesten S, Winton T. Oukcome of lung transplantation using three different cytomegalovirus prophylatic regimens. Transplant Proc. 1993;25:14:34.

78. Gould FK. Freman R, Taylor CE at at. Prophylixis and inanagement of aytomegalovirus pneumonitis afler lung tranplantation. review of experience in one center. J Heart Lung Transplant. 1943:12:695.

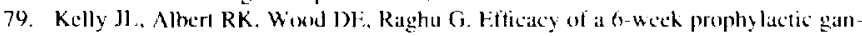
cielovir regimen and the rolk of scrial cytomegalovirus intitexly kesting in lung transplant recipients. Transplantation. 1995:59:1144.

80. Drew WL. Ives D. Lalezari JP ef al. Oral ganciclovir as maintenance Ireatment fior cytomegalowirus retinitis in patients with AIDS. N Engl J Med. 1995:333:615.

81. Kramer MR. Denning DW. Marshall SF $a$ at. Clecrative tracheobronchitis after lung tritnsplantation. A new form of invasive aspergillosis. Am Rev Respir Dis. $1991: 144: 552$

82. Yeldandi V. Laghi I: MeCabe MA et al. Aspergillhs and lung tran plantition. J Hearl Iong Tramsplam. 1995:14:883.

83. Dowling RD. Baladi $\mathrm{N}$. Zenati $\mathrm{M}$ er ad. Disruption of the aortic antistomenis atfer heart-lung transplantation. Ann Thorat Surg. 1991::49:118

84. Gryzan S, Paradis IL. Zeevi A al al. Unexpectedly high incidence of Pne'umer vistis corrimii inlection alter heart-lung transplantation implications for lung defense and allogralt survival. Am Rev Respir Dis. 1988:137:1268.

85. Gray J. Wreghtit TG. Pavel P a al. Epsecein-Barr virus infection in heast and heart-lung transplant recipients: incidence and clinteal inpakt. J Heart Lang Transplans 1995:14:640.

86. Armitage JM. Kormos RI. Stuart $S$ et al. Poxt-transplant lymphoproliferative disease in thoracic organ transplant patients: ten years of cyclosporin-based immunosuppression. J Heart L.ung Transplant 1991:10:877

87. Randlawa PS. Yousem SA. Paradis IL et al. The clinical specirum. patholeny and clonal analysis of Epstein-Barr virus-assectated lymphoproliferative disorders in heart-lung iranspliant recipients. Am J Clin Puthot. 1989:92:177

88. Nunley D, Dauber J, lacono A at al. Ten year experience with pest-1ransplant lymphoproliferative disease following lung transplantation. Am Res Re'spir (Trit Care Med 1994:149:A731.

89. Starzl TE. Porter KA, Iwatsuki S et al. Reversibility of lymphomas and lymphoproliferative lesions developing under eyclosporin steroid therapy. Lancet. 1984:1:583.

90. Shapiro RS, Chauvenet A. MeGuire W, Pearson A, McGilava P. Treatment of B cell lymphoproliferative diserders with interferon-a and intravenous gamma globulin. N Fingl J Med. 1988:318:1334.

91. Smyth RL. Higenbotlam TW, Scoll JP et al. Herpes simplex virus infection in hear-lung tramsplant recipients. Transplantation. 1990:49:735.

92. Wendt CH. Fox JMK. Herl/ MI. Paramyxovirus inlection in lung transplant recipients. J Heart Lung Transplant. 1995:14:479,

93. Wreghitt TG, Taylor CED. Bahatvalla JE. Bryant J, Wallwork J. Concurrent cy tomegalesvirus and coxsackic B virus infections in a hear-lung transplant recipient $J$ Infect. 1986:13:51

94. Carlsen St, Bergin CJ. Reactivation of tuberculowis in a doner lung after iransplantation. Am J Ridiol. 1990:154:95

95. Drumer C, Nashef S, Velly J, Martigne C, Courand I. Tuberculosis in transplanted lungs. J Heart Lung Transplant. 1993: 12:924.

96. Miller RA. Lanza 1.A, Kline JN, Geist LI. Mvobacterium nuberculosis in lung transplant recipients. Am J Respir Cril Care Med. 1945:152:374

97. Truksck EP. Bolman RM. Genton R. Pulmonary disease caused by Mucrothesterium chelonge in a heart-lung transplant recipient with obliterative bronchiolitis. Am Rev Respir Dis. 1989: 1 40:802

98. Colquhoun IW, Gascoigne AD, Gould K, Corris PA, Dark JH. Native pulmonirry sepsis after single lung transplantation. Chest. 1991:52:319.

99. Horvath J. Dummer S, Loyd J et al. Infection in the transplanted and native lung after single lung transplantation. Chest. 1993:104:681

100. Ciulli F, Tamm M. Dennis ( et al. Denor-transmitted bacterial infection in heart-lung transplantation. Transplant Proc. 1993:25:1155. 
10I Gottesdiener KM. Transplanted infections: donor-to-host transmission with the allograft. Ann Intern Med. 1989;110:1001

102. Pereira BJG, Milford EL, Kirkman RL et al. Prevalence of hepatitis C virus RNA in organ donors positive for hepatitis $C$ antibody and in the recipients of their organs. N Eng! J Med. 1992:327:910
103. Simouds RI Holmberg SD Hurwitz RL ef al Transmission of human immunodeficiency virus type 1 from a seronegative organ and tissue donor. N Engl J Med. 1992:326:726. 